OPEN ACCESS

Edited by:

Olga Vagin,

University California, Los Angeles,

USA

Reviewed by:

Pablo Artigas,

Texas Tech University Health Sciences

Center, USA

Kathleen J. Sweadner,

Massachusetts General Hospital, USA

*Correspondence:

Thomas Friedrich

friedrich@chem.tu-berlin.de

Specialty section:

This article was submitted to

Membrane Physiology and Membrane

Biophysics,

a section of the journal

Frontiers in Physiology

Received: 31 March 2016

Accepted: 03 June 2016

Published: 21 June 2016

Citation:

Friedrich T, Tavraz NN and Junghans C (2016) ATP1A2 Mutations in Migraine: Seeing through the Facets of an lon Pump onto the Neurobiology

of Disease. Front. Physiol. 7:239 doi: 10.3389/fphys.2016.00239

\section{ATP1A2 Mutations in Migraine: Seeing through the Facets of an Ion Pump onto the Neurobiology of Disease}

\author{
Thomas Friedrich ${ }^{*}$, Neslihan N. Tavraz and Cornelia Junghans \\ Department of Physical Chemistry/Bioenergetics, Institute of Chemistry, Technical University of Berlin, Berlin, Germany
}

Mutations in four genes have been identified in familial hemiplegic migraine (FHM), from which CACNA1A (FHM type 1) and SCN1A (FHM type 3) code for neuronal voltage-gated calcium or sodium channels, respectively, while ATP1A2 (FHM type 2) encodes the $\alpha_{2}$ isoform of the $\mathrm{Na}^{+}, \mathrm{K}^{+}$-ATPase's catalytic subunit, thus classifying FHM primarily as an ion channel/ion transporter pathology. FHM type 4 is attributed to mutations in the PRRT2 gene, which encodes a proline-rich transmembrane protein of as yet unknown function. The $\mathrm{Na}^{+}, \mathrm{K}^{+}$-ATPase maintains the physiological gradients for $\mathrm{Na}^{+}$and $\mathrm{K}^{+}$ions and is, therefore, critical for the activity of ion channels and transporters involved neuronal excitability, neurotransmitter uptake or $\mathrm{Ca}^{2+}$ signaling. Strikingly diverse functional abnormalities have been identified for disease-linked ATP1A2 mutations which frequently lead to changes in the enzyme's voltage-dependent properties, kinetics, or apparent cation affinities, but some mutations are truly deleterious for enzyme function and thus cause full haploinsufficiency. Here, we summarize structural and functional data about the $\mathrm{Na}^{+}, \mathrm{K}^{+}$-ATPase available to date and an overview is provided about the particular properties of the $\alpha_{2}$ isoform that explain its physiological relevance in electrically excitable tissues. In addition, current concepts about the neurobiology of migraine, the correlations between primary brain dysfunction and mechanisms of headache pain generation are described, together with insights gained recently from modeling approaches in computational neuroscience. Then, a survey is given about ATP1A2 mutations implicated in migraine cases as documented in the literature with focus on mutations that were described to completely destroy enzyme function, or lead to misfolded or mistargeted protein in particular model cell lines. We also discuss whether or not there are correlations between these most severe mutational effects and clinical phenotypes. Finally, perspectives for future research on the implications of $\mathrm{Na}^{+}, \mathrm{K}^{+}$-ATPase mutations in human pathologies are presented.

Keywords: familial hemiplegic migraine, $\mathrm{Na}^{+}, \mathrm{K}^{+}$-ATPase, human ATP1A2, neuronal hyperexcitability, protein expression, protein stability, protein targeting, structure-function studies 


\section{$\mathrm{Na}^{+}, \mathrm{K}^{+}$-ATPase IN FAMILIAL HEMIPLEGIC MIGRAINE AND OTHER INHERITED DISEASES}

Migraine is a particularly disabling pathology with a high cost for human society. The "Atlas of Headache Disorders and Resources in the World 2011" issued by the WHO reported that about $10 \%$ of the world's population suffer from migraine, with three times more women affected than men, causing 190 million days lost from work every year in Europe alone, which ranks migraine in the fourth place among neurological disorders with an estimated annual cost of about 116 billion Euros.

Migraine frequently appears with perceptional or somatosensory disturbances, which are called "aura" symptoms. These can include alterations in the field of vision (scotoma), flashes, strange smells or sounds, but also tingling, numbness or partial paresis. Familial Hemiplegic Migraine (FHM) is an autosomal dominantly inherited form of migraine with aura (MA, as opposed to migraine without aura, MO), in which the accompanying aura symptom of the typical half-sided headache is transient motor weakness (hemiparesis) that is frequently accompanied by other cortical symptoms. Four FHM types have been identified by human geneticists, from which FHM type1 (FHM1) and type 3 (FHM3) affect the genes coding for the neuronal voltage-gated P/Q-type calcium channel's $\alpha$-subunit (CACNA1A) (Ophoff et al., 1996) or the neuronal voltage-gated sodium channel's $\alpha$-subunit (SCN1A) (Dichgans et al., 2005), respectively. FHM type 2 (FHM2) is caused by mutations in the ATP1A2 gene (De Fusco et al., 2003), which encodes the isoform 2 of the human $\mathrm{Na}^{+}, \mathrm{K}^{+}$-ATPase's large catalytic $\alpha$-subunit, which in the adult central nervous system (CNS) is mainly expressed in astrocytes. Recently, a fourth FHM gene, PRRT2, has been identified (Riant et al., 2012), which encodes a proline-rich transmembrane protein of still unknown function. The PPTR2 protein was suggested to interact with the synaptosomal-associated protein 25 (SNAP-25), a t-SNARE protein, which accounts for the specificity and execution of synaptic vesicle fusion with the plasma membrane (Rizo and Südhof, 2002).

Hemiplegic migraine and MA/MO also occur as a comorbidity in proximal renal tubular acidosis (pRTA) patients carrying certain homozygous mutations in the SLC4A4 gene (encoding the $\mathrm{Na}^{+}-\mathrm{HCO}_{3}^{-}$cotransporter $\mathrm{NBCe} 1$ ), in which mutations in the other known FHM-related genes were ruled out (Suzuki et al., 2010). The NBCe1B splice variant is expressed in several tissues including brain, and its transport activity in astrocytes is thought to modulate neuronal excitability by regulating local $\mathrm{pH}$ (Chesler, 2003) suggesting that also defective $\mathrm{pH}$ regulation in the brain may be a susceptibility factor in hemiplegic and other types of migraine.

The $\mathrm{Na}^{+}, \mathrm{K}^{+}$-ATPase belongs to the large family of $\mathrm{P}$ type ATPases (Axelsen and Palmgren, 1998). The minimal unit is composed of a large catalytic $\alpha$-subunit $(\sim 1020$ amino acids, see Section Functional Insights Gained from Structural Studies) and a smaller, ancillary $\beta$-subunit $(\sim 300$ amino acids, one transmembrane domain (TM) with a heavily glycosylated ectodomain). The $\beta$-subunit is a mandatory feature of $\mathrm{K}^{+}$-countertransporting $\mathrm{P}_{2 \mathrm{C}}$-type ATPases, which assists in proper folding, assembly and targeting of the holoenzyme (Jaunin et al., 1993), and modulates cation affinities (Crambert et al., 2000). According to molecular modeling studies, the particular $\beta$-isoform serves in tuning the pump depending on its individual tilt angle (Hilbers et al., 2016) by differentially stabilizing the $\mathrm{E}_{1} \mathrm{P}\left(3 \mathrm{Na}^{+}\right)$state. There is a still unresolved controversy about the existence of higher oligomeric states (see Donnet et al., 2001; Clarke, 2009; Shattock et al., 2015; and references therein), which, if true, would allow for speculations about possible dominant-negative effects in the heterozygous state of affected patients. Based on earlier biochemical evidence (Forbush et al., 1978), a third, auxiliary $\gamma$-subunit was identified (66 amino acids, one TM) (Mercer et al., 1993), which belongs to the class of FXYD-domain containing ion transport regulator proteins (Sweadner and Rael, 2000) and is now classified as FXYD2. The FXYD family, named after the invariant amino acid motif FXYD, comprises seven members in humans (FXYD1, or phospholemman; FXYD2, or $\mathrm{Na}^{+}, \mathrm{K}^{+}$-ATPase $\gamma$-subunit; FXYD3, or Mat-8; FXYD4, or corticosteroid hormone-induced factor, CHIF; FXYD5, or "related to ion channel", RIC, also termed dysadherin; FXYD6, or phosphohippolin; FXYD7), from which all but FXYD6 were shown to associate with $\mathrm{Na}^{+}, \mathrm{K}^{+}$. ATPase $\alpha / \beta$-complexes and exerted distinct effects on pump function (see reviews by Garty and Karlish, 2006; Geering, 2006). Since the various FXYD isoforms have different tissue distribution and functional effects, with prominent expression in electrically excitable or fluid- and solute-transporting tissues, these proteins act as tissue-specific modulators of $\mathrm{Na}^{+}, \mathrm{K}^{+}$ATPase in order to fine-tune its kinetic properties according to the tissue's requirements or physiological state. In the brain, FXYD1, -6 , and -7 are the most abundant isoforms (Garty and Karlish, 2006).

Four $\alpha$-isoforms exist in humans, from which $\alpha_{1}$ is ubiquitously expressed and therefore the most indispensable isoform for cellular ion homeostasis, volume regulation, excitability etc. The $\alpha_{2}$-isoform (ATP1A2) is particularly high expressed in skeletal muscle (SM), but also heart and vascular smooth muscle (VSM) express it. In the adult central nervous system (CNS), $\alpha_{2}$ is mainly found in astrocytes, whereas $\alpha_{3}$ (ATP1A3) is neuronal-specific, and $\alpha_{4}$ has only been found in testis (spermatozoa) (see Blanco et al., 1999; Larsen et al., 2014; Shattock et al., 2015 and references therein). Two other types of human inherited diseases have been linked to $\alpha$ subunit isoforms. Mutations in the ATP1A3 gene cause Rapid Dystonia Parkinsonism (RDP, DYT12) (de Carvalho Aguiar et al., 2004), as well as Alternating Hemiplegia of Childhood (AHC) (Heinzen et al., 2012). While the ATP1A1 gene for the ubiquitously expressed $\alpha_{1}$-isoform is regarded as a susceptibility locus in human essential hypertension (Glorioso et al., 2001), congenital mutations in the gene have not been described so far. However, somatic ATP1A1 mutations were detected in aldosterone-producing adenomas (APA) and secondary hypertension (Azizan et al., 2013; Beuschlein et al., 2013). Functional studies of the ATP1A1 mutants showed loss of pump activity, strongly reduced $\mathrm{K}^{+}$affinity and augmented inward proton leak currents (see next section) at physiological potentials 
and concentrations of $\mathrm{Na}^{+}$and $\mathrm{K}^{+}$(Azizan et al., 2013). Furthermore, abnormal depolarization was observed in primary adrenal adenoma cells (Beuschlein et al., 2013), which was suggested to be the consequence of enhanced inflow of protons rather than being caused by reduced $\mathrm{Na}^{+}, \mathrm{K}^{+}$pumping (Azizan et al., 2013). This may indirectly lead to enhanced $\mathrm{Ca}^{2+}$ signaling and, consequently, enhanced aldosterone output (Beuschlein et al., 2013). Another syndrome, renal hypomagnesemia type 2 (HOMG2), an autosomal dominant pathology with isolated renal magnesium loss, is linked to mutations in the $\gamma$-subunit's FXYD2 gene. Evidence has accumulated that FXYD2 mutations cause misrouting of the $\mathrm{Na}^{+}, \mathrm{K}^{+}$-ATPase, which would lead to loss of plasma membrane protein in the kidney (Meij et al., 2000).

At least indirectly associated with $\mathrm{Na}^{+}, \mathrm{K}^{+}$-ATPase is Long QT Syndrome type 4 (LQT4), a type of cardiac arrythmia with a prolonged QT-phase in electrocardiograms (Lu and Kass, 2010) that frequently causes cardiac fibrillation and sudden death. Unlike other LQT types, LQT4 does not relate to genes of cardiac ion channels, but affects the ANK2 gene encoding ankyrin-B. Ankyrin-B serves as a scaffold protein responsible for proper targeting of $\mathrm{Na}^{+}, \mathrm{K}^{+}$-ATPase, the $\mathrm{Na}^{+}, \mathrm{Ca}^{2+}$-exchanger and the InsP3 receptor to T-tubules/sarcoplasmic reticulum microdomains in cardiac muscle cells (Mohler et al., 2005). Thus, not only molecular function, but also cellular processing must be considered in the neurobiology of disease.

FHM2 cases frequently share comorbidity with other neurological disorders, such as seizures, AHC and even epilepsy (Supplementary Table 1). This overlap is intriguing, since all these phenomena are linked to deficient regulation of the cortical excitatory/inhibitory balance (Pietrobon and Moskowitz, 2013). Most of the aura symptoms are caused by the phenomenon of Cortical Spreading Depression (CSD) (Leão, 1944) or CSDlike events that are characterized by a spreading front of excitation, which is followed by a long-lasting depression (Moskowitz et al., 2004). Whereas CSD spreads slowly over the neocortex, epilepsy is characterized by rapidly circulating waves of neuronal hyperexcitation. This pathophysiological overlap raises the question, which parameters determine the evolution of such a highly non-linear excitable system as the neocortex into one or the other hyperexcitation pattern (Ullah et al., 2015).

\section{$\mathrm{Na}^{+}, \mathrm{K}^{+}$-ATPase: FUNCTION AND STRUCTURE \\ Functional Properties of the $\mathrm{Na}^{+}, \mathrm{K}^{+}$-ATPase}

The $\mathrm{Na}^{+}, \mathrm{K}^{+}$-ATPase is an electrogenic, primary active transporter protein, which energizes the membrane of all animal cells with the characteristic electrochemical gradients for $\mathrm{Na}^{+}$and $\mathrm{K}^{+}$ions. These gradients are pivotal for the activity of secondary active transporters such as the $\mathrm{Na}^{+}, \mathrm{Ca}^{2+}$-exchanger (NCX), neurotransmitter uptake transporters or voltage-gated $\mathrm{Na}^{+}$and $\mathrm{K}^{+}$channels involved in electrical excitability. The mechanism of function is generally expressed in the form of the Post-Albers scheme (Albers, 1967; Post et al., 1972), as shown in Figure 1. In each reaction cycle, the $\mathrm{Na}^{+}, \mathrm{K}^{+}$-ATPase transports three $\mathrm{Na}^{+}$ions out of and two $\mathrm{K}^{+}$ions into the cell upon hydrolysis of one ATP molecule. The enzyme undergoes cyclic interconversions between two principal conformations, $\mathrm{E}_{1}$ and $\mathrm{E}_{2}$ and phosphorylated intermediates thereof, $\mathrm{E}_{1} \mathrm{P}$ and $\mathrm{E}_{2} \mathrm{P}$, in which a phosphate group from ATP is covalently attached to a critical aspartate residue within the SDKTGTLT motif (see next section about structural details). Upon binding of three $\mathrm{Na}^{+}$ions from the intracellular side in the ATP-bound $\mathrm{E}_{1}$ conformation, the phosphorylated intermediate with three occluded $\mathrm{Na}^{+}$ions, $\mathrm{E}_{1} \mathrm{P}\left(3 \mathrm{Na}^{+}\right)$, is formed. This is followed by a conformational change to the $\mathrm{E}_{2} \mathrm{P}\left(3 \mathrm{Na}^{+}\right)$conformation, from which $\mathrm{Na}^{+}$ions are extracellularly released. Because of the increased affinity for $\mathrm{K}^{+}$in this configuration, two $\mathrm{K}^{+}$ions bind subsequently from the extracellular side, which triggers dephosphorylation and occlusion of two $\mathrm{K}^{+}$ions in the $\mathrm{E}_{2}\left(2 \mathrm{~K}^{+}\right)$state. After another conformational change to $\mathrm{E}_{1}\left(2 \mathrm{~K}^{+}\right)$, the $\mathrm{K}^{+}$ions dissociate into the cytoplasm, a process that is speeded up by ATP binding.

Also included in Figure 1 are inhibitors of the $\mathrm{Na}^{+}$pump. Ouabain (or g-strophanthin) belongs to the family of cardiotonic steroids, from which digitalis (g-strophantidin) from the red foxglove Purpurea officinalis was in medicinal use against dropsy and cardiac insufficiency for centuries (Withering, 1785). Ouabain is used to isolate $\mathrm{Na}^{+}, \mathrm{K}^{+}$-ATPase functional activity in cells or tissue preparations and was a prerequisite for the identification of the "sodium- and potassium-transporting adenoside triphosphatase" by Chemistry Nobel Prize awardee Jens Christian Skou (Skou, 1957). The compound arrests the $\mathrm{Na}^{+}$pump with high affinity (with $\mathrm{IC}_{50}$ or $\mathrm{K}_{\mathrm{D}}$ values in the range of tens of $\mathrm{nM}$ for human $\mathrm{Na}^{+}, \mathrm{K}^{+}$-ATPase $\alpha_{1^{-}}$,

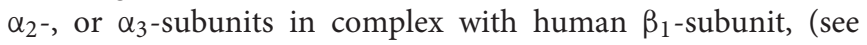
Katz et al., 2010; Weigand et al., 2014a) and references therein) by binding from the extracellular side to the $\mathrm{E}_{2} \mathrm{P}$ conformation, and this interaction competes with extracellular $\mathrm{K}^{+}$binding. In contrast, (ortho-)vanadate $\left(\mathrm{VO}_{4}^{-}\right.$) blocks the pump from the intracellular side with nanomolar affinity. With its similarity to the phosphate $\left(\mathrm{PO}_{4}^{3-}\right)$ anion and its trigonal bipyramidal structure, it serves as a transition state analog for the hydrolytic dephosphorylation of the phosphointermediate. Vanadate arrests the $\mathrm{Na}^{+}$pump in the $\mathrm{E}_{2} \mathrm{P}\left(3 \mathrm{Na}^{+}\right)$form (Glynn, 1985). Oligomycin, a macrolide antibiotic from Streptomyces, also inhibits the $\mathrm{Na}^{+}, \mathrm{K}^{+}$-ATPase (Glynn, 1985) by promoting the occlusion of $\mathrm{Na}^{+}$ions in the $\mathrm{E}_{1} \mathrm{P}$ form, and decreases the rate of $\mathrm{Na}^{+}$release from the phosphoenzyme, thereby inhibiting the $\mathrm{E}_{1} \mathrm{P} \rightarrow \mathrm{E}_{2} \mathrm{P}$ interconversion (Glynn, 1985; Skou, 1990).

The sequential translocation of $\mathrm{Na}^{+}$and $\mathrm{K}^{+}$ions requires strict cation specificity of the phosphorylation and dephosphorylation reactions, mutual changes of the apparent affinities for $\mathrm{Na}^{+}$and $\mathrm{K}^{+}$and alternating access of the cation binding sites to the extra- and intracellular medium. Active transport by an ion pump also requires the operation of two "occlusion gates" (indicated by a blue and red bar in Figure 1) shielding the bound cations from the extra- or intracellular medium, which must never be open simultaneously (Gadsby, 2009). According to the $3 \mathrm{Na}^{+} / 2 \mathrm{~K}^{+}$stoichiometry, the $\mathrm{Na}^{+}, \mathrm{K}^{+}$ATPase produces an outward movement of one positive charge per cycle and generates a pump current. The major electrogenic event has been shown to take place during extracellular release (or reverse binding) of $\mathrm{Na}^{+}$(Fendler et al., 1985; Gadsby et al., 


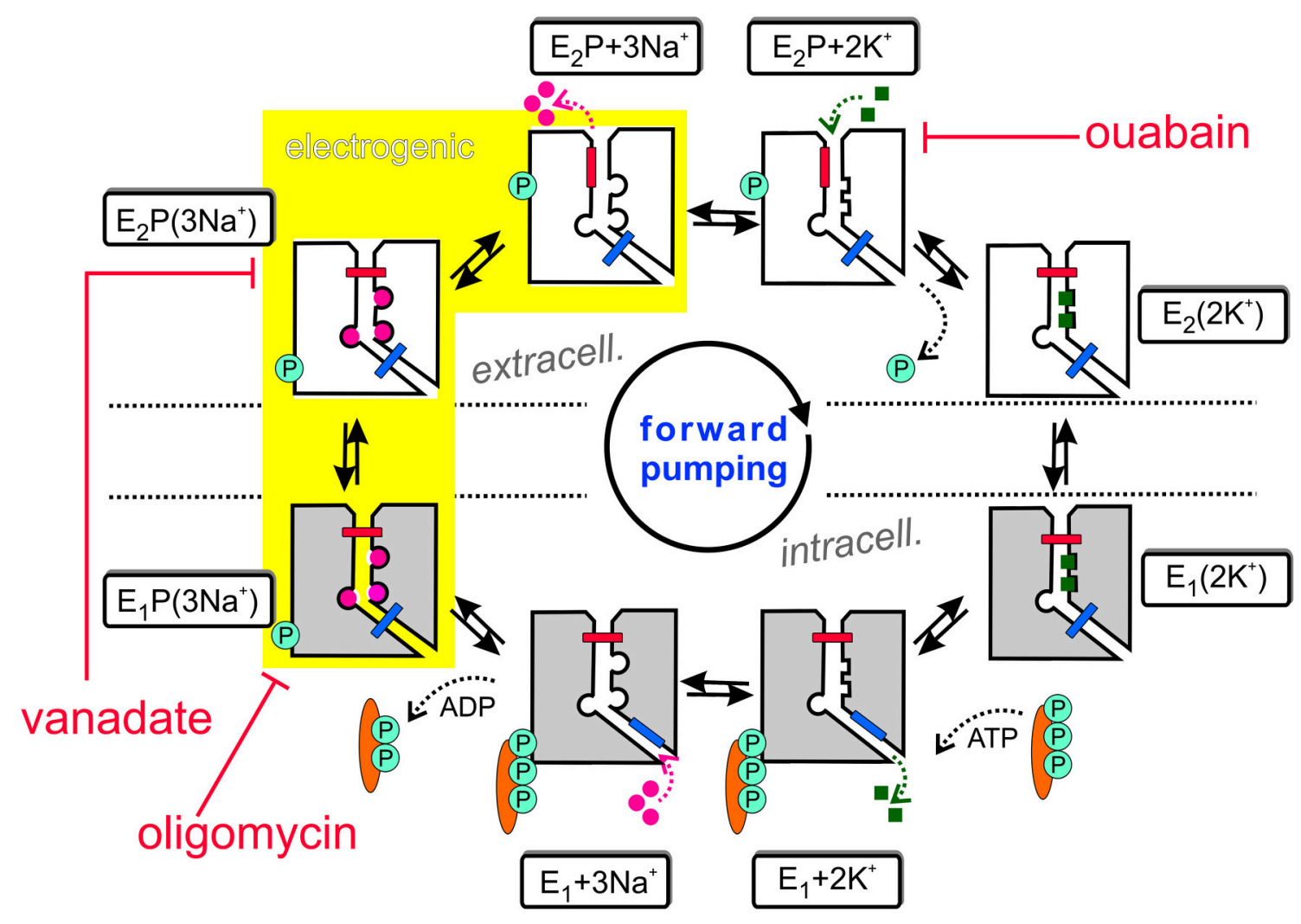

FIGURE 1 | The Post-Albers reaction mechanism of the $\mathrm{Na}^{+}, \mathrm{K}^{+}-$ATPase. See text for details.

1985; Nakao and Gadsby, 1986; Gadsby and Nakao, 1989; Rakowski et al., 1991; Rakowski, 1993; Wuddel and Apell, 1995) within a sequence of coupled partial reactions, which is underlaid in yellow in Figure 1. Electrogenicity arises from passage of $\mathrm{Na}^{+}$ ions through a narrow, high-field "access channel" to/from the extracellular space (Läuger, 1979; Gadsby et al., 1993; Hilgemann, 1994; Sagar and Rakowski, 1994; Rakowski et al., 1997; Holmgren et al., 2000; Holmgren and Rakowski, 2006). This term, combined with the notion of its "fractional depth", is frequently used to denote that an ion passes a certain fraction of the transmembrane electric field in order to reach or exit from its binding site. In the same way as the existence of a positive slope of the stationary current-voltage (I-V) curve in the negative voltage range indicates electrogenic extracellular $\mathrm{Na}^{+}$release (or reverse binding) (Nakao and Gadsby, 1989), the negative slope in the I-V curve at positive voltages (Rakowski et al., 1991) suggests that also $\mathrm{K}^{+}$ions bind within an extracellular access channel, albeit of smaller fractional depth (see Section Electrophysiological Assays: The Two-Electrode Voltage Clamp for more details). There might well be other steps in the catalytic cycle, which contribute to the total electrogenicity of the $\mathrm{Na}^{+}$pump, such as intracellular $\mathrm{Na}^{+}$binding, as shown by Pintschovius et al. (1999) as well as Apell and Karlish (2001).

Electrophysiology has elucidated another functional detail of the $\mathrm{Na}^{+}, \mathrm{K}^{+}$-ATPase, namely the ouabain-sensitive "leak currents", which were first observed at negative voltages in the absence of extracellular $\mathrm{Na}^{+}$and $\mathrm{K}^{+}$, and are augmented by extracellular acidification. Initially reported by Rakowski et al. (1991) and later investigated in more detail by Efthymiadis et al. (1993), Wang and Horisberger (1995), Rettinger (1996) and Li et al. (2006), this property has for a long time been merely recognized as a footnote in $\mathrm{Na}^{+}$pump research, until structural and functional evidence highlighted the critical role of protons in the transport cycle, as indicated by mutations that interfere with a C-terminal pathway for protons (see Section Functional Insights Gained from Structural Studies) to access the cation binding pocket (Morth et al., 2007; Poulsen et al., 2010). Recently, it was demonstrated that the proton leak inward current is a property inherent to $\mathrm{Na}^{+}, \mathrm{K}^{+}$-ATPase that also flows at physiological $\mathrm{K}^{+}$ and $\mathrm{Na}^{+}$concentrations and membrane potentials (Mitchell et al., 2014; Vedovato and Gadsby, 2014), even in native cells, i.e., in the presence of the pump's normal regulatory subunit phospholemman, which is prevalent in cardiac tissue (Mitchell et al., 2014). Vedovato and Gadsby concluded that inward proton leak exploits the reversibility of a subset of conformational changes associated with extracellular $\mathrm{Na}^{+}$release from the phosphorylated enzyme. Although such a back-step of phosphorylated $\mathrm{Na}^{+}, \mathrm{K}^{+}$-ATPase that enables proton import is not required for completion of the $3 \mathrm{Na}^{+} / 2 \mathrm{~K}^{+}$transport cycle, it readily occurs during $\mathrm{Na}^{+}, \mathrm{K}^{+}$transport when external $\mathrm{K}^{+}$ 
ion binding and occlusion are retarded, and it occurs more frequently when the probability for extracellular proton access is increased by acidification (Vedovato and Gadsby, 2014). The protons presumably pass through the $\mathrm{Na}^{+}$-selective binding site III (which may be in fact two sites, see Section Functional Insights Gained from Structural Studies) via the carboxylates of Glu-958 to Asp-930 via the intervening hydroxyl of Tyr-775 (ATP1A2 numbering), which is distinct from the principal pathway of the $\mathrm{Na}^{+}$and $\mathrm{K}^{+}$ions passing through binding site II. From the simultaneous occurrence of $\mathrm{Na}^{+}, \mathrm{K}^{+}$exchange and $\mathrm{H}^{+}$import during the same conformational cycle of a single molecule, the $\mathrm{Na}^{+}, \mathrm{K}^{+}$-ATPase classifies as a hybrid transporter, although the physiological or pathophysiological significance of pumpmediated proton inflow still has to be clarified (Vedovato and Gadsby, 2014). By performing experiments over an expanded range of extracellular $\mathrm{pH}\left(\mathrm{pH}_{\mathrm{o}}\right)$ values and meticulous ion competition assays, Mitchell et al. delineated a previously unrecognized inhibitory action of extracellular protons on the leak current, which occurs in addition to the $\mathrm{pH}_{\mathrm{o}}$-induced leak stimulation (Mitchell et al., 2014). Based on the strong voltage dependence of the $\mathrm{pH}_{\mathrm{o}}$-induced leak stimulation, these authors concluded that protons leak through the site responsible for strong $\mathrm{Na}_{\mathrm{o}}$ - and voltage-dependent inhibition of pump current, which must be site III, in agreement with (Vedovato and Gadsby, 2014). The $\mathrm{pH}_{\mathrm{o}}$-dependent inhibition of the leak, although profoundly enhanced by decreasing $\mathrm{pH}_{\mathrm{o}}$, was nevertheless only weakly voltage-dependent, similar to the inhibition by $\mathrm{Na}_{0}^{+}$or extracellular $\mathrm{K}^{+}$binding, suggesting that inhibition of the leak current by external cations $\left(\mathrm{H}^{+}, \mathrm{Na}^{+}\right.$or $\left.\mathrm{K}^{+}\right)$requires binding to sites I and II that are not responsible for the $\mathrm{Na}^{+}, \mathrm{K}^{+}$-ATPase's voltage dependence (Mitchell et al., 2014).

The inward current was found to be augmented by mutations at the $\mathrm{Na}^{+}, \mathrm{K}^{+}$-ATPase's C-terminus (Yaragatupalli et al., 2009; Meier et al., 2010; Poulsen et al., 2010; Vedovato and Gadsby, 2010; Paulsen et al., 2012), and sometimes further enhanced with increasing extracellular $\left[\mathrm{Na}^{+}\right]$, which conforms with an earlier proposal that $\mathrm{Na}^{+}$ions might flow along what has been referred to as the $\mathrm{Na}^{+}, \mathrm{K}^{+}$-ATPase "leak" pathway, a process that is promoted by extracellular protons (Vasilyev et al., 2004). The studied C-terminal mutations frequently correlate with drastic decreases in the apparent affinity for extracellular and intracellular $\mathrm{Na}^{+}$(Toustrup-Jensen et al., 2009, 2014), because C-terminal mutations interfere with $\mathrm{Na}^{+}$binding site III.

Whether or not $\mathrm{Na}^{+}, \mathrm{K}^{+}$pump-mediated proton uptake plays a physiological or pathological role is still unclear. Vedovato and Gadsby pointed out, that already at physiological $\mathrm{pH}_{\mathrm{o}}$, and even more so at decreased $\mathrm{pH}_{\mathrm{o}}$ in a pathophysiological situation, the $\mathrm{Na}^{+}, \mathrm{K}^{+}$pump will import one or several protons downhill in each ATPase transport cycle. Thus, proton inward leak might significantly accompany $\mathrm{Na}^{+}, \mathrm{K}^{+}$pumping at the normal negative resting potentials of neurons as well as cardiac and skeletal muscle cells, if extracytoplasmic $\mathrm{pH}$ became sufficiently low, as e.g., during vigorous muscle exercise, or in cardiac or cerebral ischemia, since $\mathrm{Na}^{+}, \mathrm{K}^{+}$-ATPase densities in muscle, nerve, and heart can be very high $\left(\geq 1000 \mu \mathrm{m}^{2}\right)$. It is also conceivable that the known limitation of $\mathrm{H}^{+}$-ATPasemediated acidification of early endosomes by endocytosed $\mathrm{Na}^{+}, \mathrm{K}^{+}$-ATPase might be the direct consequence of $\mathrm{Na}^{+}, \mathrm{K}^{+}$ pump-mediated flow of protons from the endosome lumen to the cytoplasm (Vedovato and Gadsby, 2014). The importance of cortical $\mathrm{pH}$ regulation is underlined by the involvement of certain homozygous mutations in the $\mathrm{NBCe} 1 \mathrm{Na}^{+}-\mathrm{HCO}_{3}^{-}$ cotransporter, which is expressed in astrocytes, in pRTA patients that additionally suffer from hemiplegic migraine (Suzuki et al., 2010). Glial cell depolarization usually results from elevated extracellular $\left[\mathrm{K}^{+}\right]$, which causes glial cell acid secretion via inward electrogenic $\mathrm{Na}^{+}-\mathrm{HCO}_{3}^{-}$cotransport, resulting in depolarization-induced alkalosis (DIA) in the cytoplasm of glial cells (Chesler, 2003). The extracellular acidosis that occurs simultaneously to DIA makes the surrounding neuronal cells less excitable because excitatory NMDA receptors are blocked by protons (Suzuki et al., 2010). Therefore, extracellular acidosis suppresses neuronal excitability, and the reduction of DIA due to enhanced proton inward transport by mutant glial $\mathrm{Na}^{+}, \mathrm{K}^{+}$-ATPase could also create a positive feedback loop of increased neuronal activity leading to further NMDA-mediated neuronal hyperactivity, depolarization of brain cells, and CSD (Suzuki et al., 2010). Although increased proton leak has only been reported for the R937P mutation in ATP1A2 (Poulsen et al., 2010), this may not be an isolated observation, since no other ATP1A2 allele has so far been scrutinized for altered proton leak.

\section{Functional Insights Gained from Structural Studies}

For the $\mathrm{Na}^{+}, \mathrm{K}^{+}$-ATPase, high-resolution structures of different reaction cycle intermediates are available, which provided an atomic-level understanding of active cation transport coupled to enzymatic catalysis. Structures include the $\mathrm{Rb}^{+}$-occluded $\mathrm{E}_{2} \mathrm{P}$ like conformation $\left[\mathrm{Rb}_{2}^{+}\right] \mathrm{E}_{2} \cdot \mathrm{MgF}_{4}^{2-}$ (Morth et al., 2007), which was further refined in the $\mathrm{E}_{2} \cdot 2 \mathrm{~K}^{+} \cdot \mathrm{P}_{\mathrm{i}}$ (also stabilized by $\mathrm{MgF}_{4}^{2-}$ ) structure that revealed the full arrangement of the $\beta$-subunit (Shinoda et al., 2009), the low-affinity ouabain- and $2 \mathrm{~K}^{+}$-bound $\mathrm{E}_{2} \cdot 2 \mathrm{~K}^{+} \cdot \mathrm{P}_{\mathrm{i}}$ (also stabilized by $\mathrm{MgF}_{4}^{2-}$ ) structure (Ogawa et al., 2009), the high-affinity ouabain-bound $\mathrm{E}_{2} \mathrm{P}$-like state with $\mathrm{Mg}^{2+}$ bound to the cation binding pocket (Ogawa et al., 2009), the $\mathrm{Na}^{+}$bound $\mathrm{E}_{1} \cdot\left(\mathrm{AlF}_{4}^{-}\right) \cdot \mathrm{ADP} \cdot 3 \mathrm{Na}^{+}$structure (stabilized with $\mathrm{AlF}_{4}^{-}$) of an intermediate preceding the $\mathrm{Na}^{+}$-occluded $\mathrm{E}_{1} \mathrm{P}\left(3 \mathrm{Na}^{+}\right)$ state (Kanai et al., 2013), and a comparable $\left[\mathrm{Na}_{3}^{+}\right] \mathrm{E}_{1} \mathrm{P}$-ADP state in complex with $\mathrm{AlF}_{4}^{-}$, with $\mathrm{Na}^{+}$saturation stabilized by oligomycin (Nyblom et al., 2013). These structural data, together with the wealth of intermediate structures determined for the related SERCA $\mathrm{Ca}^{2+}$-ATPase from sarcoendoplasmic reticulum (Olesen et al., 2007), provide a comprehensive concept of the catalytic mechanism carried out by the $\mathrm{Na}^{+}$pump.

Figure 2 shows the arrangement of the $\alpha-, \beta$ - and $\gamma$ subunit of the $\mathrm{Na}^{+}, \mathrm{K}^{+}$-ATPase in the $2 \mathrm{Rb}^{+}$-bound $\mathrm{E}_{2} \mathrm{P}$-like conformation (Morth et al., 2007). Several distinct domains can be distinguished on the $\alpha$-subunit, with $10 \mathrm{TM}$ segments forming the TM domain harboring the coordination sites for cations and the central TM5 helix, which extends into the central P (phosphorylation) domain. The $\mathrm{P}$ domain harbors the P-type ATPase consensus motif ${ }^{373}$ SDKTGTLT ${ }^{380}$ with the intermediately phosphorylated Asp-374 (all numbering refers to 
human ATP1A2), which is surrounded by the ${ }^{612} \mathrm{MVTGD}^{616}$ and ${ }^{713} \mathrm{DG}(\mathrm{V} / \mathrm{M}) \mathrm{ND}^{717}$ motifs and the critical Lys-605. Nucleotide binding occurs in the $\mathrm{N}$ domain, and the A (actuator) domain serves as an anchor for the movement of the $\mathrm{N}$ domain by performing a hinge-like movement during the conformational cycle to bring the conserved ${ }^{217}$ TGES $^{220}$ motif into close proximity with ${ }^{612} \mathrm{MVTGD}^{616}$ to expedite dephosphorylation. Movement of the A domain also entails a piston-like movement of TM helices 1 and 2. The crystal structures also highlighted a particularly crucial arrangement of the enzyme's C-terminal sequence ${ }^{1013}$ WVEKETYY $^{1020}$. The first part of this motif assumes an $\alpha$-helical structure accommodated between the TM of the $\beta$-subunit and the TM7 and TM10 helices, and the two terminal tyrosines project into a binding pocket between TM7, TM8, and TM5, with the terminal Tyr-1020 interacting with Lys770 on TM5 and Arg-937 in the loop connecting TM8 and TM9 (Morth et al., 2007). Deletion of the terminal KETYY sequence resulted in a 26 -fold reduction of $\mathrm{Na}^{+}$affinity, reminiscent of the effect of mutations of putative $\mathrm{Na}^{+}$coordinating residues. This has prompted investigations of the functional importance of C-terminal residues by studying deletions, mutations of the terminal tyrosines, or C-terminal extensions. These studies showed that alterations in the C-terminal sequence entail drastic decreases in $\mathrm{Na}^{+}$affinity and enhance the propensity of the mutant pumps to permit inward proton leak (Yaragatupalli et al., 2009; Meier et al., 2010; Poulsen et al., 2010; Vedovato and Gadsby, 2010, 2014; Paulsen et al., 2012). This has given rise to the concept that the C-terminal pathway occupied by the terminal tyrosines defines a mandatory access route for intracellular protons to the $\mathrm{Na}^{+}$binding site III to bring about stoichiometric $3 \mathrm{Na}^{+} / 2 \mathrm{~K}^{+}$transport, in which Arg-937 and Asp-923 play a critical role (Poulsen et al., 2010).

From the two "common" cation binding sites, site I is made up from five oxygen atoms (from Thr-776 main chain, and from Ser-779, Asn-780 (all TM5), and Asp-808 (TM6) side chains), and one water molecule, whereas site II is coordinated by the main chain carbonyls of Val-327, Ala-328, and Val-330 (all TM4) and the side chain oxygens of Asn-780, Glu-783 (TM5) and Asp-808 (TM6), and possibly Glu-332 (TM4) (Shinoda et al., 2009). Of note, the TM5 helix is unwound at Asn-780 to create sufficient space for cation coordination. The unwinding is due to Pro-782; both amino acids reside in the highly conserved ${ }^{779}{ }^{S N I P E}{ }^{783}$ motif. In the two $\mathrm{E}_{1} \cdot \mathrm{P} \cdot \mathrm{ADP} \cdot 3 \mathrm{Na}^{+}$-like structures, the geometry for $\mathrm{Na}^{+}$coordination at the two "common" sites is essentially the same, with similar TM5 helix unwinding. Regarding the location of $\mathrm{Na}^{+}$binding site III, the structure by Kanai et al. (2013) identified two slightly different locations in the two protomers of the crystallographic unit, and the study by Nyblom et al. (2013) had to resolve a similar ambiguity by proposing two sites, IIIa and IIIb, from which site IIIa is surrounded by Glu-958, Tyr775, and Thr-811, and site IIIb adjacent to Thr-778, Gln-858, Gln-927, and Asp-930, with a sufficiently clear electron density to identify IIIb as primary $\mathrm{Na}^{+}$binding site III. Mutational analysis and electrophysiology suggested that site IIIa is a transient $\mathrm{Na}^{+}$ binding site during extracellular $\mathrm{Na}^{+}$release. The latter was also inferred from proton leak currents of mutant enzymes (see below), which showed that site IIIa mutations (Y775F, Q958A)

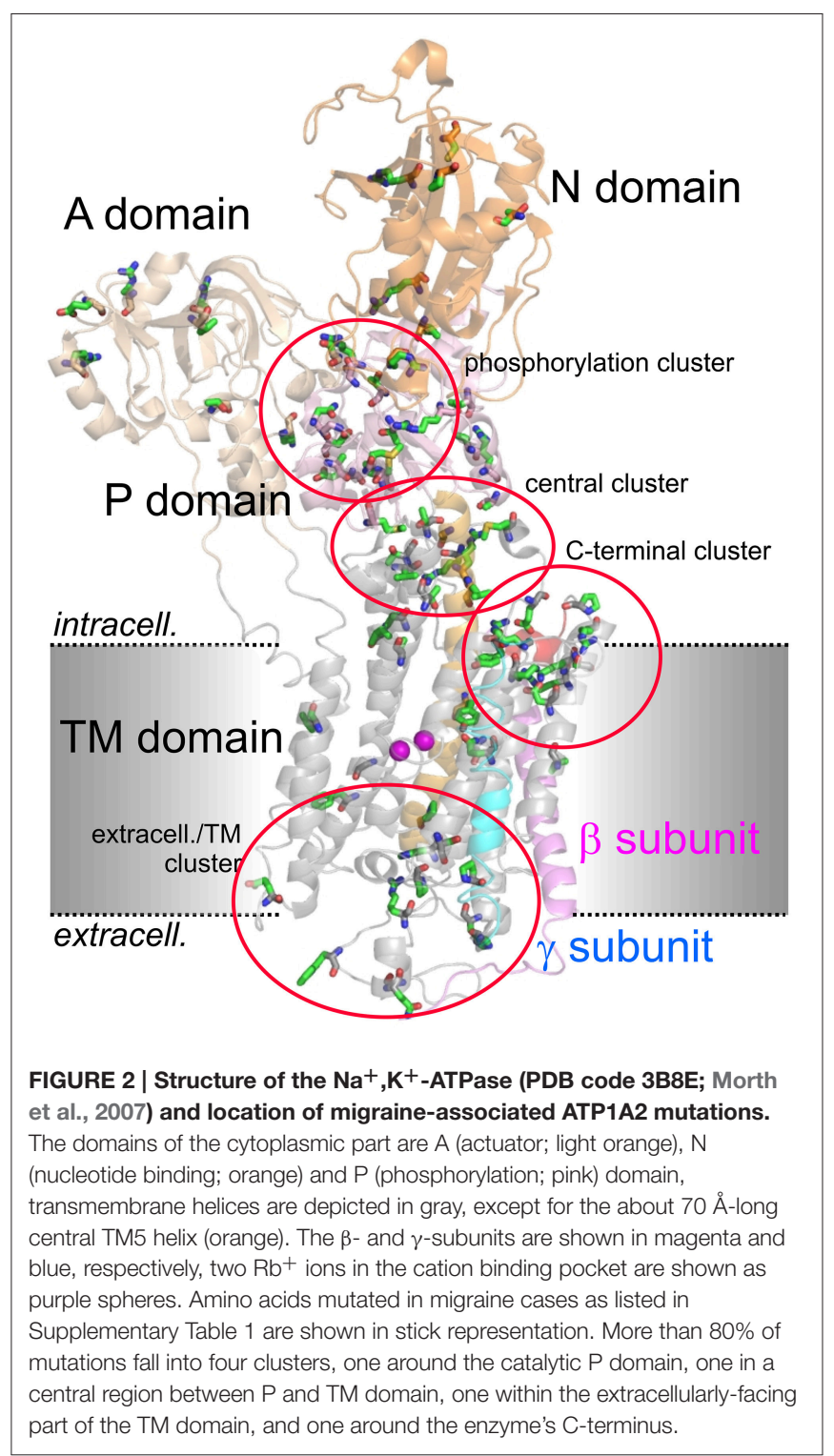

permitted leak currents in the absence of extracellular $\mathrm{Na}^{+}$but with $\mathrm{Na}^{+}$closing the leak, whereas site IIIb mutations (D930E and Q858N) permitted leak currents with and without $\mathrm{Na}^{+}$. This gave rise to the concept that protonation of Asp-930 is associated with voltage-dependent release of $\mathrm{Na}^{+}$from site IIIb via site IIIa to the extracellular space. The proton leak current can occur under conditions when either no $\mathrm{Na}^{+}$ions are bound or when only the two common sites are occupied by $\mathrm{Na}^{+}$ions (Nyblom et al., 2013), or, as later shown, by protons (Mitchell et al., 2014). Then, site IIIa is accessible to an extracellular proton, which upon application of negative voltage can move via site IIIb to the cytoplasm, thus making site IIIa accessible for an extracellular proton again, which eventually leads to a sustained inward proton leak current. This notion was corroborated and refined by two comprehensive electrophysiological studies (Mitchell et al., 2014; Vedovato and Gadsby, 2014). 


\section{THE HEADACHE OF ATP1A2 MUTATIONS: NEUROBIOLOGY OF MIGRAINE}

How can $\mathrm{Na}^{+}, \mathrm{K}^{+}$-ATPase dysfunction be linked to migraine? In the case of CACNA1A and SCN1A mutations, functional disturbances are typically gain-of-function effects, and mutated channels, e.g., exhibit an abnormal residual activity in the inactivated state, which leads to prolonged cation influx into neurons, thus causing, inter alia, depolarization and lowering of the activation threshold. Whether ATP1A2 mutations in FHM2 classify as gain- or loss-of-function phenomena is not that clearcut. While many mutations abolish or largely reduce $\mathrm{Na}^{+}, \mathrm{K}^{+}$ pumping implying loss-of-function, others are characterized by subtle changes in voltage dependence (Supplementary Table 1). In these cases, a shift of the pump current's I-V curve may entail loss-of-function in a particular voltage range, but gainof-function in another. From the viewpoint of $\mathrm{Na}^{+}, \mathrm{K}^{+}$-ATPase cation transport, a first clue is obtained from the fact that hyperkalemia is a known CSD and migraine trigger. Since the transporter in neurons or astrocytes removes extracellular $\mathrm{K}^{+}$, dysfunction of the pump can lead to elevated extracellular $\mathrm{K}^{+}$ levels, which cause depolarization and reduce the activation threshold. But also $\mathrm{Na}^{+}$extrusion by the enzyme is critical, since, e.g., the activity of secondary active transporters depends on the $\mathrm{Na}^{+}$gradient across the membrane. First, the $\mathrm{Na}^{+}, \mathrm{Ca}^{2+}$ exchanger (NCX1) utilizes $\mathrm{Na}^{+}$import for the extrusion of $\mathrm{Ca}^{2+}$, and failure to efficiently remove cytosolic $\mathrm{Ca}^{2+}$ during neuronal activity leads to $\mathrm{Ca}^{2+}$ accumulation in intracellular stores, from which it is then more heavily released during an action potential, and again, hyperexcitability is the outcome. Second, excitatory neurotransmitter uptake transporters (EAATs) also couple to the $\mathrm{Na}^{+}$gradient, and failure to remove neurotransmitters such as glutamate from the synaptic cleft again results in sustained hyperexcitability (see Figure 3 ).

It is generally accepted that cortical spreading depression (CSD) is the neurophysiological correlate of migraine aura (Pietrobon and Striessnig, 2003). Therefore, neurobiologists split up the question concerning the pathogenic mechanism of migraine into two parts: (1) What is the relation of ATP1A2 mutations to CSD, and (2), what are the links between CSD and cortical pain perception? Although the existence of a "migraine generator" in the brainstem has not been completely ruled out (Pietrobon and Moskowitz, 2013), there is currently no doubt, that CSD plays a central role in the pathophysiology of migraine.

\section{From ATP1A2 Mutations to CSD: The Glutamatergic Hypothesis}

From clinical studies, it is known that neurophysiological abnormalities in sensory information processing (which are most intense $12-24 \mathrm{~h}$ before a migraine attack during the premonitory phase, but disappear a few hours before or during the attack) change in intensity in temporal relation to the migraine episode. This suggests that some intrinsic mechanism in the brains of migraineurs progressively increases the dysfunction in central information processing and the susceptibility to a migraine trigger. These mechanisms may lead to the premonitory symptoms and, above a certain threshold of cortical dysfunction in response to migraine triggers, may eventually ignite CSD. Depending on the study, the cortex of migraineurs is hyperexcitable as a consequence of either enhanced excitation or reduced inhibition, or is hypoexcitable, or has a lower preactivation level. Thus, also here, rather than merely hypo- or hyperexcitability, defective regulation of cortical excitability and the consequently reduced ability to maintain the cortical excitatory/inhibitory (E/I) balance appears to underlie abnormal sensory processing (Pietrobon and Moskowitz, 2013, 2014).

The analysis of experimental CSD in FHM knockin mouse models suggests that CSD is a key migraine trigger, since both FHM1 and FHM2 knockin mice showed a lower electrical stimulation threshold for CSD induction and faster CSD propagation (van den Maagdenberg et al., 2004, 2010; Leo et al., 2011). In FHM1 knockin mice carrying the mild R192Q mutation or the severe S218L mutation in CACNA1A, the strength of CSD facilitation as well as the severity of the subsequent neurological motor deficits and the propensity of CSD to propagate into subcortical structures correlated with the strength of the gain-of-function of the CACNA1A channel and the severity of the clinical phenotype (van den Maagdenberg et al., 2004, 2010). Interestingly, the velocity of propagation and the frequency of CSDs elicited by local application of high $\left[\mathrm{K}^{+}\right]$were larger in female than in male FHM1 mouse mutants, in correspondence with the higher migraine prevalence of females (Eikermann-Haerter et al., 2009). However, such gender differences were not found in FHM2 knockin mice carrying the (heterozygous) W887R mutation in ATP1A2 (Leo et al., 2011). More importantly, the analysis of cortical synaptic transmission in FHM1 knockin mice revealed differential effects of FHM1 mutations at excitatory and inhibitory synapses: Excitatory synaptic transmission on cortical pyramidal cells was enhanced as a consequence of increased action potential-evoked $\mathrm{Ca}^{2+}$ influx and increased glutamate release, and enhanced short-term synaptic depression during trains of action potentials was observed. In contrast, inhibitory neurotransmission at cortical fast spiking interneuron synapses was not altered in FHM1 knockin mice, although being initiated by P/Q-type $\mathrm{Ca}^{2+}$ channels as well (Tottene et al., 2009). Although these considerations were restricted to specific cortical subcircuits, the differential effect of FHM1 mutations on excitatory and inhibitory neurotransmission may produce hyperexcitation in certain brain conditions, but may leave the excitatory/inhibitory balance intact in others, consistent with the episodic nature of the disease (Pietrobon and Moskowitz, 2013). The gain-offunction of glutamate release at synapses of cortical pyramidal cells can explain the facilitation of experimental CSD in FHM1 knockin mice, which supports a model of CSD initiation, in which CACNA1A-dependent release of glutamate from cortical pyramidal cell synapses and activation of NMDA receptors play a key role in the positive feedback cycle that ignites CSD (Pietrobon and Moskowitz, 2013). It was suggested that excessive NMDA receptor-mediated glutamatergic transmission following impaired clearance of glutamate by astrocytic processes surrounding glutamatergic synapses (the "tripartite synapse" see 


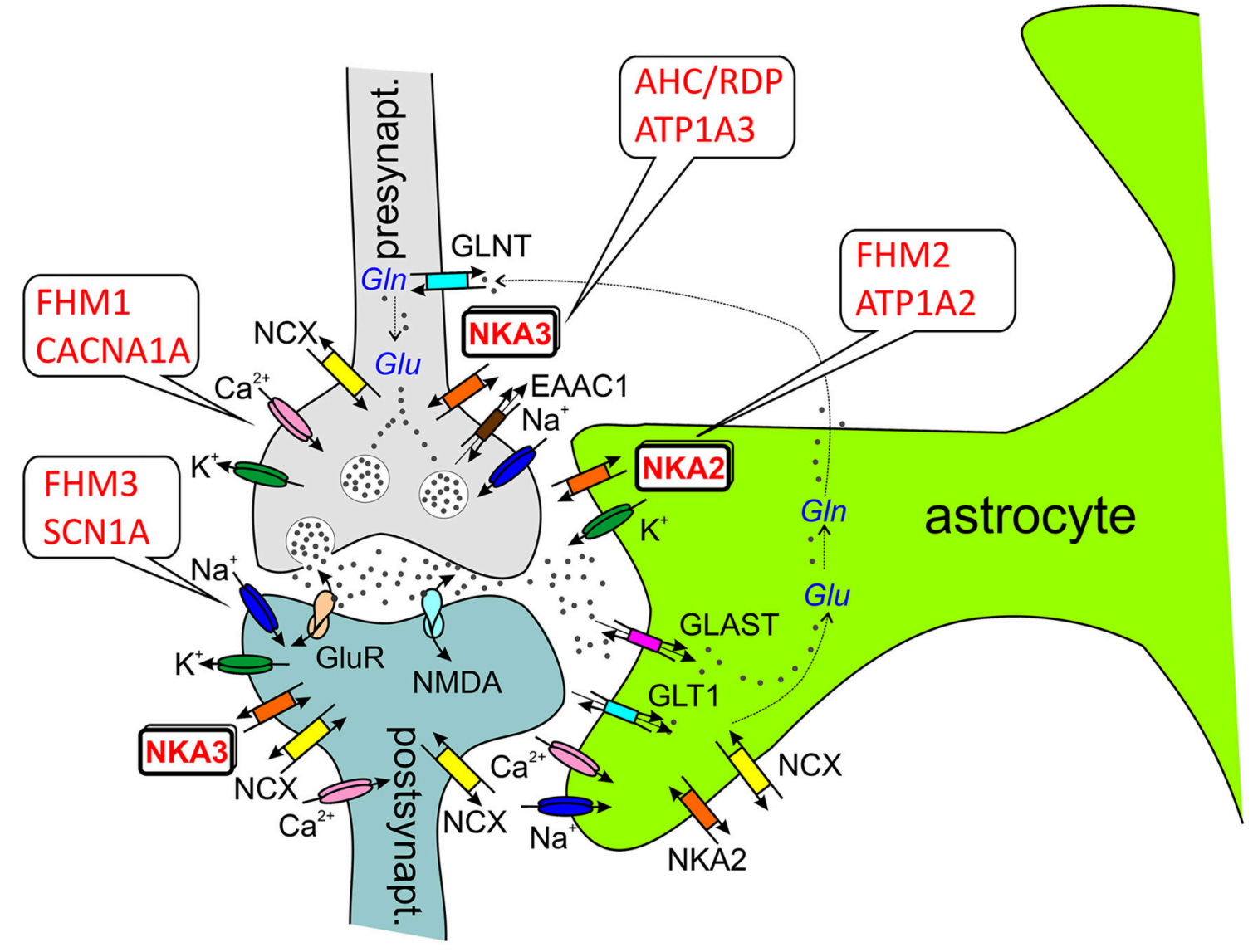

FIGURE 3 | ATP1A2 and ATP1A3 in the tripartite synapse (Perea et al., 2009). Most glutamatergic synapses are in contact with astrocytic processes, which express a high density of excitatory amino acid transporters (EAATs, e.g., GLT1, GLAST), which are crucial for the synaptic glutamate (Glu) clearance. In astrocytes, glutamate is converted to glutamine by glutamine synthetase as part of glutamate recycling. lon channels involved in electrical excitation are indicated by the respective cations, $\mathrm{Na}^{+}, \mathrm{K}^{+}$, and $\mathrm{Ca}^{2+}$. Abbreviations: GLAST (EAAT1), glutamate/aspartate transporter; GLT1 (EAAT2), glutamate transporter; GLNT, glutamine transporter; GluR, (metabotropic) glutamate receptor; NKA2/3, $\mathrm{Na}^{+}, \mathrm{K}^{+}$-ATPase $\alpha_{2}{ }^{-} \alpha_{3}$-subunit; NMDA, ionotropic glutamate receptor; NCX, Na ${ }^{+}, \mathrm{Ca}{ }^{2+}$-exchanger; Gln, glutamine.

Figure 3), where the $\alpha_{2} \mathrm{Na}^{+}, \mathrm{K}^{+}$-ATPase is functionally coupled to glutamate transporters (Cholet et al., 2002; Rose et al., 2009), may underlie the enhanced CSD susceptibility in the FHM2 mouse model (Leo et al., 2011). This has given rise to the "glutamatergic" hypothesis. In the nervous system, the $\mathrm{Na}^{+}, \mathrm{K}^{+}$ATPase $\alpha_{2}$-isoform is expressed primarily in neurons during embryonic development and at birth, but almost exclusively in astrocytes in the adult (Moseley et al., 2003). Whereas neurons express $\alpha_{1}$ - and $\alpha_{3}$-subunits (with distinctly different subcellular localization pattern, Juhaszova and Blaustein, 1997), astrocytes express $\alpha_{1}$ - and $\alpha_{2}$-subunits, and studies on primary cultured rat astrocytes suggest, that the contribution of $\alpha_{2}$ to extracellular $\mathrm{K}^{+}$clearance is about $30 \%$ of total $\mathrm{Na}^{+}, \mathrm{K}^{+}$-ATPase activity (Larsen et al., 2014). However, $\alpha_{1}$ and $\alpha_{2}$ are differentially distributed in astrocytes. Whereas $\alpha_{1}$ is evenly present at the plasma membrane, $\alpha_{2}$ rather shows a reticular distribution, like the $\mathrm{Na}^{+}, \mathrm{Ca}^{2+}$-exchanger NCX1, where it may play an important role in $\mathrm{Ca}^{2+}$ signaling (Juhaszova and Blaustein, 1997; see Section ATP1A2 and $\mathrm{Ca}^{2+}$ Signaling), and it was found to be heavily present in glial leaflets surrounding dendritic spines and axodendritic synapses, where it colocalizes with GLAST and GLT-1 glutamate transporters (Cholet et al., 2002). This functional link to glutamate transporters in astrocytic processes surrounding glutamatergic synapses suggests specific roles in the regulation of glutamate clearance (Pietrobon, 2007; Pietrobon and Moskowitz, 2013). However, ATP1A2 could have a crucial role in extracellular $\mathrm{K}^{+}$clearance by astrocytes (Larsen et al., 2014), similar to VSM (DiFranco et al., 2015) and cardiomyocytes (Stanley et al., 2015). Due to the stronger voltage-dependent inhibition of $\alpha_{2}$ pumps (which is even augmented for the glial $\alpha_{2} / \beta_{2}$ subunit composition compared to $\alpha_{1} / \beta_{1}$ pumps) and the lower extracellular $\mathrm{K}^{+}$ affinity, $\alpha_{2}$ pumps are essentially inactive at the normal, negative resting potential and at normal extracellular $\left[\mathrm{K}^{+}\right]$, whereas it will be fully activated during cell depolarization and elevated $\mathrm{K}^{+}$. This provides a substantial reserve pumping activity for $\mathrm{K}^{+}$clearance during strong cortical activity (Larsen et al., 2014). Yet, although ATP1A2 is a key player in $\mathrm{K}^{+}$clearance, this aspect has been considered less important for the pathophysiology of migraine 
because the duration of the CSD was not prolonged in the FHM2 mouse model (Leo et al., 2011). These findings collectively suggest that ATP1A2 mutations in migraine primarily cause a disorder of glutamatergic neurotransmission with defective regulation of the $\mathrm{E} / \mathrm{I}$ balance in the brain (Pietrobon and Moskowitz, 2013).

\section{From CSD to Trigeminovascular Nociception: The Neuroinflammatory Hypothesis}

CSD can be triggered by local elevations of extracellular $\left[\mathrm{K}^{+}\right]$ as a consequence of the hyperactivity of neuronal circuits in the cerebral cortex. Of note, CSD is a slowly propagating wave of strong neuronal and glial depolarization accompanied by depression of electroencephalographic (EEG) activity and by a large increase in extracellular $\left[\mathrm{K}^{+}\right]$(Pietrobon and Striessnig, 2003). To explain pain generation, the so-called vascular theory prevailed in the past, which proposed that abnormal dilation of meningeal and/or extracranial arteries causes pain, since these are the only cerebral structures endowed with primary pain receptors. However, clinical and experimental evidence rendered this hypothesis implausible, since vasodilation is neither necessary nor sufficient to cause migraine pain (Pietrobon and Striessnig, 2003). It currently emerges that the migraine headache depends on the activation and sensitization of trigeminal nociceptors that innervate the meninges and their large blood vessels. Mediators of noxious pain, such as protons, nitric oxide, arachidonic acid, and serotonin, besides glutamate and other neurotransmitters, are released during CSD. The neuroinflammatory hypothesis suggests that these substances may activate trigeminal nociceptors innervating blood vessels in the pia mater, and, via axon collaterals, dural trigeminal afferents and/or may slowly access the meningeal afferents after disruption of the blood-brain barrier, thus eventually activating central trigeminovascular neurons in the trigeminocervical complex. Activation of the meningeal afferents leads to release of proinflammatory vasoactive neuropeptides, e.g., the calcitonin gene-related peptide (CGRP). These processes may promote "sterile" neurogenic inflammation in the dura mater and sustain the activation or sensitization of the trigeminovascular afferents (Pietrobon and Striessnig, 2003).

\section{ATP1A2 and $\mathrm{Ca}^{2+}$ Signaling}

The concerted action between $\mathrm{Na}^{+}, \mathrm{K}^{+}$-ATPase and NCX1 is particularly important, since $\alpha_{2}$ - and $\alpha_{3}$-isoforms (but not $\alpha_{1}$ ) were found to co-immunoprecipitate with NCX1 in rat brain membrane preparations. This, together with colocalization studies by immunocytochemistry suggested that plasma membrane microdomains containing NCX1 and $\mathrm{Na}^{+}$ pumps with $\alpha_{2}$ - or $\alpha_{3}$-subunits in neurons and astrocytes form $\mathrm{Ca}^{2+}$ signaling complexes with plasma membrane-subjacent "junctional" endoplasmic reticulum (jER) microdomains containing ryanodine receptors and sarco/endoplasmic reticulum $\mathrm{Ca}^{2+}$-ATPase (Lencesova et al., 2004), as found previously for the junctional sarcoplasmic reticulum (jSR) microdomains in VSM cells as well as astrocytes (Juhaszova and Blaustein, 1997). In line with this notion, it was shown on primary cultured astrocytes from wild-type $\alpha_{2}(+/+)$, knockout $\alpha_{2}(-/-)$, and $\alpha_{2}(+/-)$ heterozygous mouse fetuses that graded loss of ATP1A2 activity successively increases $\mathrm{Ca}^{2+}$ signaling (Golovina et al., 2003). The typical volume of such a jS/ER or "PLasmERosome" (Blaustein and Golovina, 2001) compartment is sub-femtoliter in size, in which 1000 ions already account for micromolar concentrations. As a consequence, a 50\% loss in $\mathrm{Na}^{+}$pump activity may indeed be a matter of concern already on short time scales.

\section{Beyond the Glutamatergic Hypothesis: Cell Volume as a Control Parameter?}

One aspect attracting the attention of neurophysiologists is the importance of cell volume changes that inevitably accompany the massive changes in ion concentrations during seizures, spreading depression, or anoxic depolarization. During CSD, extracellular $\left[\mathrm{K}^{+}\right]$increases to $30-60 \mathrm{mM}$, but extracellular $\left[\mathrm{Na}^{+}\right]$and $\left[\mathrm{Cl}^{-}\right]$decrease to $50-70 \mathrm{mM}$ (Pietrobon and Moskowitz, 2014). The concomitant massive uptake of $\mathrm{Na}^{+}$and $\mathrm{Cl}^{-}$by the $\mathrm{Na}^{+}, \mathrm{K}^{+}, 2 \mathrm{Cl}^{-}$transporter (NKCC1) of astrocytes and simultaneous water uptake through aquaporins leads to astrocyte swelling (Larsen et al., 2014). In this respect, it is interesting to note that CSD can be optically monitored in cortical preparations by measuring the so-called intrinsic optical signal (IOS), a neuroimaging technique that measures cortical reflectance changes with high temporal and spatial resolution. The parameters, which the IOS is sensitive to, are changes in light scattering, blood volume, oxy-/deoxyhemoglobin balance and cytochrome oxidation (Ba et al., 2002). Light scattering (monitored at $850 \mathrm{~nm}$ ) is particularly sensitive to cell volume changes, and this signal component coincides with the electrical signal of the spreading wavefront. New modeling tools and concepts in computational neuroscience have recently identified cell volume as a critical control parameter that separates CSD from seizures as well as other types of spreading depolarization (Wei et al., 2014; Ullah et al., 2015). These approaches use stunningly sophisticated models of neuronal excitability based on a Hodgkin-Huxley-type framework of differential equations that includes the activity of $\mathrm{Na}^{+}, \mathrm{K}^{+}$ion pumps (Cressman et al., 2009; Ullah et al., 2009), conservation of particles and charge, and accounts for the energy required to restore ionic gradients (Dahlem et al., 2013; Ullah et al., 2015). According to Larsen et al. (2014), $\mathrm{K}^{+}$-induced swelling of astrocytes is mediated by NKCC1, but NKCC1 does not contribute to extracellular $\mathrm{K}^{+}$clearance, an activity exclusively spared for $\alpha_{2}$-containing $\mathrm{Na}^{+}, \mathrm{K}^{+}$-ATPase. Moreover, these authors found indications that glial $\mathrm{Na}^{+}, \mathrm{K}^{+}$-ATPase acts to dampen cell swelling during clearance of stimulus induced $\left[\mathrm{K}^{+}\right]$. So the action of glial $\mathrm{Na}^{+}, \mathrm{K}^{+}$-ATPase could be four-fold: (1) direct astrocytic $\mathrm{K}^{+}$buffering and clearance, (2) glutamate clearance (indirect via glutamate transporters), (3) osmolyte transport to dampen cell swelling, and (4) direct repolarizing activity due to electrogenic charge transport. Given the emphasis that computational neuroscientists currently place on cell volume as a control parameter discriminating between seizures and CSD 
(Ullah et al., 2015), it will be rewarding to study the relation between $\mathrm{Na}^{+}$pump dysfunction and cell volume regulation in the CNS more closely by experiment and theory.

Computational neuroscientists outlined that the premonitory symptoms of a migraine attack, such as the abnormal responses to food, stress, or light, instead of mistaking them as trigger factors themselves, should rather be considered as indicators of a systemic transition at a culminating point that follows some universal pattern, which is determined by dynamic network biomarkers (DNBs) (Dahlem et al., 2013, 2014). In contrast to traditional biomarkers (e.g., biochemical substances) that are statically enhanced or increased in the pathological state, DNBs are dynamical features of biological networks (also substances or, in general, signals), which, though highly fluctuating, are strongly correlated only during the premonitory phase. Such DNBs characterizing the premonitory period are known for lung injury disease, liver and lymphoma cancer, but still need to be identified for migraine. However, their identification could help to develop strategies for early therapeutic intervention. A new scientific discipline, translational computational neuroscience, which still needs to be inaugurated by close interactions between clinicians, experimentalists and theoreticians, may fuse dynamical systems theory with control theory in order to drive innovations in therapeutic brain stimulation to treat neurological diseases based on theoretical concepts (Dahlem et al., 2013).

\section{THE WEAL AND WOE OF HAVING $\mathrm{Na}^{+}, \mathrm{K}^{+}$-ATPase $\alpha_{2}$-SUBUNITS IN CERTAIN TISSUES}

What is the advantage of having different $\mathrm{Na}^{+}, \mathrm{K}^{+}$-ATPase $\alpha$ isoforms expressed in a tissue-specific manner, and which other pathophysiological effects could be expected in the case of $\alpha_{2}$-subunit haploinsufficiency besides the migraine phenotype? Whereas the $\alpha_{1}$-isoform is ubiquitously expressed and most indispensable for the organism, the $\alpha_{2}$-isoform is expressed mainly in heart, skeletal, and vascular smooth muscle, brain, lung, and adipocytes. The $\alpha_{3}$-isoform occurs mainly in neurons and ovaries, as well as in developing hearts of rat and in adult human heart and in white blood cells, and $\alpha_{4}$ is found in sperm, where it is required for sperm motility (see Lingrel, 2010, and references therein). The possibility to coassemble with three $\beta$-isoforms and up to seven FXYD proteins adds up further complexity. The tissue and subcellular distribution of the $\alpha_{2}$-isoform, in particular its selective expression in electrically excitable cells, or the cells that surround them, or in VSM suggests that $\alpha_{2}$ could also modulate excitability and contractility in heart and skeletal muscle as well as in the vasculature (Radzyukevich et al., 2004). The functional properties that distinguish $\alpha_{2}$ - from $\alpha_{1}$-containing $\mathrm{Na}^{+}$pumps define the importance of this isoform in muscle (DiFranco et al., 2015; Stanley et al., 2015) and astrocytes (see Section From ATP1A2 Mutations to CSD: The Glutamatergic Hypothesis). Stanley et al. showed recently that the unusually steep voltage dependence of ion transport of $\alpha_{2}$ containing $\mathrm{Na}^{+}$pumps in the range of physiological potentials, which is even exacerbated by assembly with $\beta_{2}$, provides a strong reservoir of pumping activity during the cardiac action potential, while keeping it inactive at normal resting potentials. In addition, as earlier found by Han et al. (2009), it was demonstrated that $\alpha_{2}$ pumps in cardiomyocytes (Stanley et al., 2015) and skeletal muscle (DiFranco et al., 2015) have reduced affinity for extracellular $\mathrm{K}^{+}$, allowing them to be readily stimulated by physiological rises in $\mathrm{K}_{\mathrm{o}}^{+}$occurring under exercise. The distinct (cardiomyocytes) and almost exclusive (skeletal muscle) localization of the $\alpha_{2}$-isoform to T-tubules (see DiFranco et al., 2015; Stanley et al., 2015, and references therein), which are highly diffusion-restricted spaces where $\mathrm{K}_{\mathrm{o}}^{+}$may rise to tens of millimolar during muscle activity (DiFranco et al., 2015), further supports the notion that $\alpha_{2}$ provides a safety net for $\mathrm{K}_{\mathrm{o}}^{+}$clearance and $\mathrm{Na}^{+}$extrusion that is only recruited on request.

Should cardiac, skeletal muscle or vasculature deficits accompany the phenotype of ATP1A2 haploinsufficiency? In the heart, the low (about 10-15\%) overall proportion of the $\alpha_{2}$-isoform and the presence of potentially compensating $\alpha_{1}$ in T-tubules may alleviate loss of $\alpha_{2}$ activity. Results from transgenic animals seem to depend on the knockout strategy. James et al. investigated a global germline deletion of one copy of $\alpha_{2}$ (heterozygous $\alpha_{2}(+/-)$ knockout mice) and observed cardiac hypercontractility as a result of increased $\mathrm{Ca}^{2+}$ transients during the contractile cycle, in accordance with the proposed role of $\alpha_{2}$ in cardiac inotropy (James et al., 1999). Later, Rindler et al. generated mice with tissue-targeted knockout of $\alpha_{2}$ that resulted in more than $90 \%$ loss of $\alpha_{2}$ exclusively in the cardiovascular system (Rindler et al., 2011) or in the heart (Rindler et al., 2013). These authors found cardiac and vascular contractility unaltered. Similar contrasting results were obtained regarding the effects of $\alpha_{2}$ knockouts in the vasculature, in which the ratio of $\alpha_{2}$ to $\alpha_{1}$ is $30 \% / 70 \%$ (Shelly et al., 2004). Whereas heterozygous $\alpha_{2}(+/-)$ knockout mice had elevated systolic blood pressure, increased myogenic tone and arterial contractility (Shelly et al., 2004; Rindler et al., 2011), the cardiovascular knockout model showed normal basal blood pressure and vascular contractility suggesting that expression of $\alpha_{2}$ in cardiac myocytes and vascular smooth muscle is not involved in the regulation of basal blood pressure. Possibly, $\alpha_{2}$ in another cell type might be responsible for the hypertension observed in global $\alpha_{2}(+/-)$ mice (Rindler et al., 2011). In rare cases, vascular abnormalities coincide with hemiplegic migraine, such as pulmonary arterial hypertension (Montani et al., 2013) and reversible cerebral vasoconstriction (Hermann et al., 2013).

The situation should definitely be different in skeletal muscle, in which $\alpha_{2}$ comprises nearly $90 \%$ of total $\alpha$-subunit content (He et al., 2001) and is almost exclusively present in T-tubules (DiFranco et al., 2015). However, the $\alpha_{2}$-isoform does not set resting ion gradients ( $\mathrm{He}$ et al., 2001) or the resting potential (Radzyukevich et al., 2004, 2013) in skeletal muscle, the canonical roles of the $\mathrm{Na}^{+}, \mathrm{K}^{+}$-ATPase in most other cell types, due to its profound voltage-dependent inhibition at the about $-90 \mathrm{mV}$ resting potential in skeletal muscle and its lower $\mathrm{K}^{+}$affinity compared to $\alpha_{1}$. In accordance, the $\alpha_{1}$-isoform localized to the surface sarcolemma provides up to $75 \%$ of the basal $\mathrm{Na}^{+}, \mathrm{K}^{+}$ transport needed to stabilize ion gradients and membrane potential at rest. However, $\alpha_{1}$ operates at the upper edge of 
its regulatory range for activation by $\mathrm{K}^{+}$, and the tremendous transport capacity of $\alpha_{2}$ pumps needs to be recruited during exercise. Skeletal muscle also differs from other excitable tissues because its resting potential is set by $\mathrm{ClC}$ chloride channels (Pedersen et al., 2016), as illustrated by the hyperexcitability of skeletal muscle in myotonia congenita, a muscle disease resulting from loss-of-function mutations in the $\mathrm{ClC}$ - 1 gene (Koch et al., 1992). Also for skeletal muscle effects, studies on transgenic mice are not fully conclusive. Whereas increased isometric force, hypercontractility and increased fatique was observed in isolated skeletal muscle from heterozygous $\alpha_{2}(+/-)$ mice (He et al., 2001), the $\alpha_{2}(+/-)$ animals themselves did not fatique faster than wild-type animals (Moseley et al., 2007). Increased fatique was observed in skeletal muscle-targeted $\alpha_{2}(+/-)$ knockout animals and muscle preparations derived thereof (Radzyukevich et al., 2013). Of note, a 2.5-fold upregulation of $\alpha_{1}$ was observed in these skeletal muscle $\alpha_{2}(-/-)$ knockout animals, and even some presence of $\alpha_{1}$ in T-tubules was observed suggesting that some partial compensation by $\alpha_{1}$ could take place (Radzyukevich et al., 2013). Since the largest effects were observed in the severe skeletal muscle knockout system but not in the global $\alpha_{2}(+/-)$ heterozygotes, it seems plausible that the vast capacity of $\alpha_{2}$ to cope with tremendous physiological load increases during physical exercise may keep sufficient reserve at hand that $50 \%$ loss in $\alpha_{2}$ may not entail an additional skeletal muscle phenotype in FHM2.

\section{METHODS FOR EXPERIMENTAL ASSESSMENT OF $\mathrm{Na}^{+}, \mathrm{K}^{+}$-ATPase FUNCTION}

\section{Ouabain Survival Assays}

For the investigation of functional consequences of FHM2 mutations, the so-called ouabain survival assays on HeLa cells are most frequently applied (Bassi et al., 2004; de Vries et al., 2007). The mutations are introduced into an ouabain-resistant ATP1A2 backbone carrying the Q116R/N127D double mutation in the TM1-2 loop, which produces $\mathrm{IC}_{50}$ values in the 100 micromolar range (Price and Lingrel, 1988). HeLa cells are either transiently or stably transfected and put under micromolar ouabain stress, which is sufficient to block the endogenous $\mathrm{Na}^{+}$pumps, so that only cells expressing an ATP1A2 mutant construct with sufficient residual activity can survive. The heterozygous state of patients can be mimicked by co-transfecting equal amounts of wildtype and mutant ATP12A2 DNA in order to address possible dominant-negative effects (De Fusco et al., 2003). The cell line for transfection should be carefully chosen as highlighted by the differences observed from ouabain survival assays on COS7 and HeLa cells for the W887R mutation (De Fusco et al., 2003; Leo et al., 2011). Whereas the mutant protein did not confer cell survival in both cell lines, (De Fusco et al., 2003) reported normal cellular distribution and plasma membrane expression in COS7 cells, but (Leo et al., 2011) found drastically reduced protein level and a mainly intracellular distribution in HeLa cells suggesting that COS7 cells might be prone to saturation artifacts, a common threat in transient transfection studies.

\section{Biochemical Assays}

Molecular function can be addressed by biochemical assays, which requires recombinant protein production in appropriate expression hosts such as stably transfected mammalian cells (Toustrup-Jensen et al., 2014), or insect cells (e.g., Sf9 derived from the fall armyworm Spodoptera frugiperda, Weigand et al., 2014b). Yeast cells (Pichia pastoris) have also been used (Cohen et al., 2005), but this host has not yet been employed for the study of FHM2 mutations. Subsequently, the whole set of biochemical techniques can be performed (see Glynn, 1985; Kaplan, 2002, for reviews), such as the "classical" ATPase (Skou, 1957) or phosphorylation assays, in which also the effects of different $\mathrm{Na}^{+}$ and $\mathrm{K}^{+}$concentrations, the steady-state phosphoenzyme level, conformational preference, ouabain binding and sensitivity, and vanadate sensitivity can be determined. The maximum phosphorylation levels obtained in the presence of oligomycin are used to measure the concentration of active enzyme sites, which, together with ATP hydrolysis rates, are used to determine the maximum turnover number (Glynn, 1985; Vilsen, 1995), thus yielding a thorough characterization of enzymatic properties.

\section{Electrophysiological Assays: The Two-Electrode Voltage Clamp}

The cation transport function of the $\mathrm{Na}^{+}, \mathrm{K}^{+}$-ATPase as such can only be investigated in intact cells, which maintain the extra/intracellular sidedness of substrate access and allow for the application of a membrane (or more general: electrochemical) potential load on cation transport. $\mathrm{Na}^{+}, \mathrm{K}^{+}$transport and the most significant properties relating to the electrogenicity of the $\mathrm{Na}^{+}$pump are determined by electrophysiology, mostly by applying the two-electrode voltage clamp technique on oocytes from the frog Xenopus laevis (Stühmer and Parekh, 1995). This technique allows one to study the dependence of $\mathrm{Na}^{+}, \mathrm{K}^{+}$pump currents on extracellular $\left[\mathrm{K}^{+}\right],\left[\mathrm{Na}^{+}\right]$, ouabain and voltage, so that the complex interplay between $\mathrm{Na}^{+}$and $\mathrm{K}^{+}$at the externally facing cation binding sites can be analyzed.

Typical $\mathrm{Na}^{+}, \mathrm{K}^{+}$pump currents, as can be recorded with the two-electrode voltage clamp on Xenopus laevis oocytes, are shown in Figure 4A together with the voltage and extracellular $\left[\mathrm{K}^{+}\right]$dependence (Figure 4B), from which $\mathrm{K}_{0.5}\left(\mathrm{~K}^{+}\right)$values for half-maximal pump current stimulation can be determined (Figure 4C), which symbolize the voltage dependence of the enzyme's apparent affinity for extracellular $\mathrm{K}^{+}$.

In the absence of extracellular $\mathrm{K}^{+}$and at high extracellular $\left[\mathrm{Na}^{+}\right]$, the enzyme is restricted to the partial reaction sequence underlaid in yellow in Figure 1 that accounts for ouabainsensitive "transient" currents in response to voltage pulses (Figure 5A). Extracellular release of $\mathrm{Na}^{+}$ions occurs in three distinct steps, from which only the deocclusion and release of the first $\mathrm{Na}^{+}$ion is major electrogenic (Holmgren et al., 2000). This step is rate-limited by the preceding (presumably non-electrogenic) $\mathrm{E}_{1} \mathrm{P} \rightarrow \mathrm{E}_{2} \mathrm{P}$ conformational change and cation deocclusion, which gives rise to the startling observation that the forward rate constant for $\mathrm{Na}^{+}$release is not voltage-dependent (see the flat progression of rate constants in Figure 5B at positive voltages). However, in the reverse direction, the reverse binding 

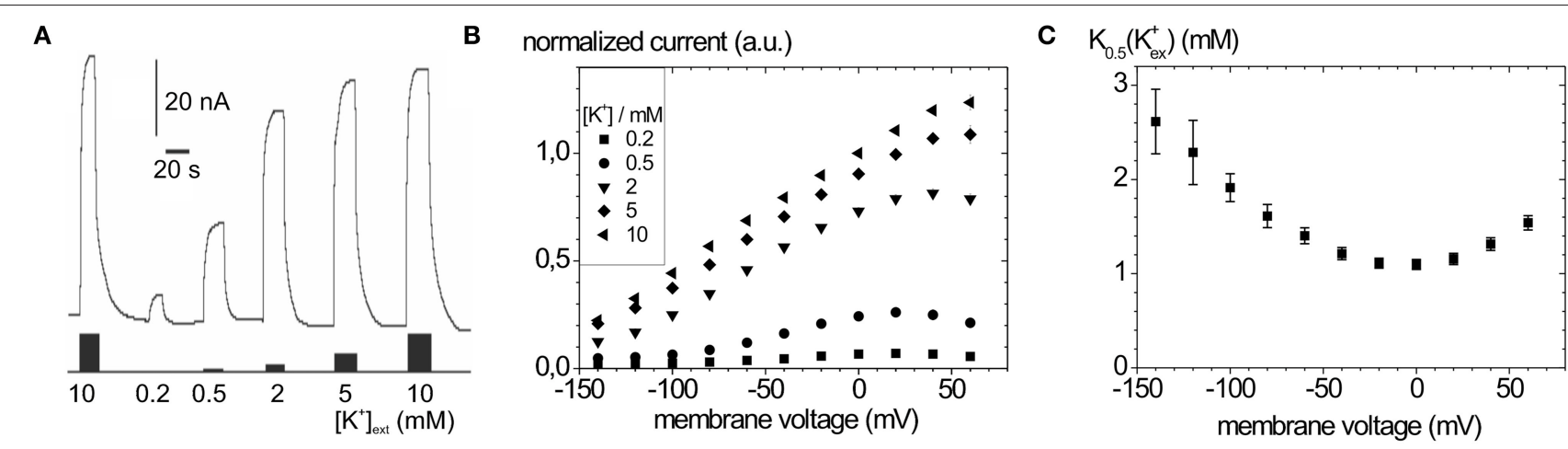

FIGURE 4 | Stationary $\mathrm{Na}^{+} / \mathrm{K}^{+}$pump currents of the $\mathrm{Na}^{+}, \mathrm{K}^{+}$-ATPase (human ATP1A2) from two-electrode voltage clamp experiments on $X$. laevis oocytes. (A) Pump currents in response to different extracellular $\left[\mathrm{K}^{+}\right]$at $-30 \mathrm{mV}$ holding potential, (B) I-V curves for different $\left[\mathrm{K}^{+}\right]$ext at high [Na ${ }^{+}$ext (100 $\mathrm{mM}$ ). (C) $\mathrm{K}_{0.5}\left(\mathrm{~K}^{+}\right.$ext) values from fits of a Hill function to the $\left[\mathrm{K}^{+}\right]$dependent pump current amplitudes at different potentials from $(\mathbf{B})$.

of $\mathrm{Na}^{+}$ions from the extracellular side induced by negative voltage pulses occurs with a strongly voltage-dependent rate constant (see the steeply rising rate constants in Figure 5B at negative voltages). Following release of the first $\mathrm{Na}^{+}$ion, the high-field access channel to the other $\mathrm{Na}^{+}$occlusion sites is restructured such that the exit of the remaining two $\mathrm{Na}^{+}$ions contributes only little to the overall electrogenicity. In terms of the "access channel" model, positive voltage pulses drive $\mathrm{Na}^{+}$ ions extracellularly out of the access channel resulting in ouabainsensitive "transient" currents with positive polarity. Conversely, negative voltage pulses promote the reverse binding of $\mathrm{Na}^{+}$ions to the binding sites in $\mathrm{E}_{2} \mathrm{P}$ and induce negative transient currents (Figure 5A). Due to the electrogenicity of reverse binding of extracellular $\mathrm{Na}^{+}$, the occupancy of the $\mathrm{Na}^{+}$binding sites is controlled by $\left[\mathrm{Na}^{+}\right]_{\mathrm{o}}$ and voltage. The amount of charge moved in response to a certain voltage step $Q(V)$ follows a characteristic, sigmoidal, Boltzmann-type function (see Figure 5C):

$$
Q(V)=Q_{\min }+\frac{Q_{\max }-Q_{\min }}{1+e^{-\frac{z_{q} \cdot F}{R \cdot T}\left(V-V_{0.5}\right)}}
$$

which is used to fit the experimentally obtained $Q(V)$ curves. Here, $Q_{\min }$ and $Q_{\max }$ are the saturation values of $Q(V), F$ is the Faraday constant, $R$ the molar gas constant, $T$ the absolute temperature in $\mathrm{K}, V$ the membrane voltage, and $z_{q}$ the slope factor or equivalent charge. This distribution is centered at a halfmaximal voltage $\left(V_{0.5}\right)$, at which $50 \%$ of $\mathrm{Na}^{+}$binding sites of the pump molecules are occupied. Since the $\mathrm{Na}^{+}$uptake/release steps are kinetically coupled to the $\mathrm{E}_{1} \mathrm{P} \longleftrightarrow \mathrm{E}_{2} \mathrm{P}$ conformational transition, $50 \%$ of the enzyme molecules are in $\mathrm{E}_{2} \mathrm{P}$ and $50 \%$ are in $\mathrm{E}_{1} \mathrm{P}$ at this stage. Thus, the $V_{0.5}$ value at a given $\left[\mathrm{Na}^{+}\right]_{\mathrm{o}}$ is a characteristic parameter for each $\mathrm{Na}^{+}, \mathrm{K}^{+}$-ATPase isozyme (or mutant), and since $V_{0.5}$ shifts with the extracellular $\left[\mathrm{Na}^{+}\right]$, changes in $V_{0.5}$ induced by mutations indicate changes in the apparent affinity for $\mathrm{Na}_{\mathrm{o}}^{+}$. Positive shifts of $V_{0.5}$ indicate an increased apparent $\mathrm{Na}^{+}$affinity and vice versa.

The equivalent charge $z_{q}$ indicates the electrogenicity of the $\mathrm{Na}^{+}$transport step, i.e., which fraction of the transmembrane field is "sensed" by a unitary charge moved or, conversely, which fraction of a charge encounters the full transmembrane field during an elementary charge-moving event.

Of late, the ouabain-sensitive leak currents are investigated by electrophysiology as well, since mutations interfering with a C-terminal access pathway for protons drastically affect cation affinities (Morth et al., 2007; Poulsen et al., 2010). Thus, especially C-terminal mutations identified in FHM2 and AHC have been scrutinized for suspicious leak current activity (Poulsen et al., 2010; Li et al., 2015). As an example, the leak currents of the $\mathrm{Na}^{+}$ pump that occur upon deletion of the two C-terminal tyrosines of the $\alpha$-subunit are shown in Figure 6. Figure 6A shows ouabainsensitive transient currents of the ATP1A2- $\triangle \mathrm{YY}$ mutant in the absence of extracellular $\mathrm{K}^{+}$and $\left[\mathrm{Na}^{+}\right]_{\mathrm{o}}=100 \mathrm{mM}$ (Meier et al., 2010). Compared to the transient currents of the WT enzyme (Figure 5A), the "ON" transient currents of the mutant do not decay to zero at negative voltages, but a steady inward current results, which is augmented with increasing $\left[\mathrm{Na}^{+}\right]_{\mathrm{o}}$ (Figure 6B). This phenomenon was also observed by Yaragatupalli et al. (2009), Poulsen et al. (2010) and Vedovato and Gadsby (2010).

\section{ATP1A2 MUTATIONS CORRELATED WITH CLINICAL MIGRAINE CASES}

To date, about 81 ATP1A2 mutations have been reported in migraine-correlated neurological disease cases in the literature. A complete list is provided in Supplementary Table 1 together with information about the diagnosed diseases, the location of the mutated residues within the structure of the $\mathrm{Na}^{+}, \mathrm{K}^{+}$-ATPase (see Figure 2) and, if available, a brief summary of functional consequences of the mutations. The vast majority (about 60) of the mutations were classified as FHM. Moreover, about 25 mutations were diagnosed in sporadic cases of hemiplegic migraine, SHM, (with overlap in the case of G815R, R908Q, P979L, which were identified in different unrelated pedigrees or individuals) showing that mutations in the ATP1A2 gene locus substantially account for de novo mutations causing hemiplegic migraine. About $10 \%$ of ATP1A2 mutations were identified 

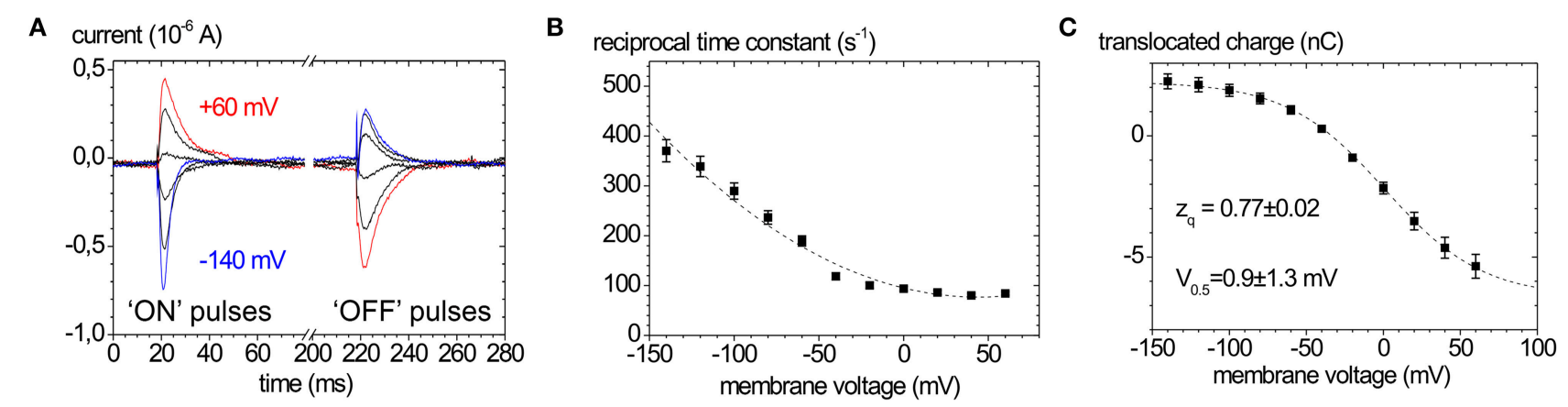

FIGURE 5 | Properties of ouabain-sensitive transient currents of the $\mathbf{N a}^{+}, \mathbf{K}^{+}-\mathbf{A T P a s e}$. (A) Transient currents evoked by pulses from $-30 \mathrm{mV}$ to voltages between +60 and $-140 \mathrm{mV}$ in $-40 \mathrm{mV}$ decrements measured on human ATP1A2 in two-electrode voltage clamp experiments on X. laevis oocytes ("ON" currents), and from pulses back to $-30 \mathrm{mV}$ ("OFF" pulses). (B) Reciprocal time constants from fits of a single exponential function to the current traces in (A). (C) $Q$ ( $)$ distribution from the improper integrals of the transient current signals ("OFF" pulses) from (A) with the parameters obtained from fits of a Boltzmann-type function to the data. The Q(V) distribution from "ON" transient currents would be obtained by multiplying the above curve with (-1).
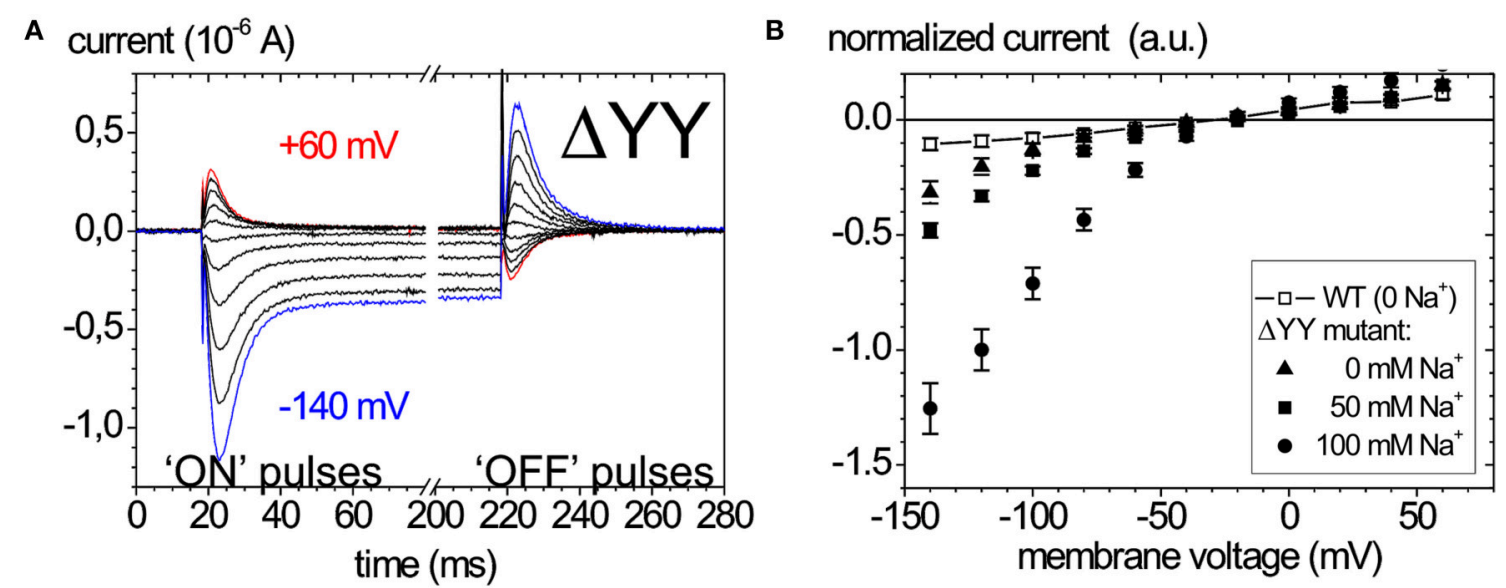

FIGURE 6 | Leak currents of the $\mathbf{N a}^{+}, \mathbf{K}^{+}$-ATPase upon mutation of the $\alpha$-subunit's $\mathbf{C}$-terminus. (A) Ouabain-sensitive transient currents measured at $\left[\mathrm{K}^{+}\right]_{\mathrm{O}}=0,\left[\mathrm{Na}^{+}\right]_{\mathrm{O}}=100 \mathrm{mM}(\mathrm{pH} 7.4)$ upon pulses from $-30 \mathrm{mV}$ to voltages between +60 and $-140 \mathrm{mV}$ in $-40 \mathrm{mV}$ decrements for mutant ATP1A2- $\Delta \mathrm{YY}$ in two-electrode voltage clamp experiments on X. laevis oocytes ("ON" currents), and from pulses back to -30 mV ("OFF" pulses). (B) [Na+] ${ }_{0}$ dependence of the current-voltage curves of the steady-state inward leak currents (closed symbols), the leak currents of the WT enzyme at zero [Na ${ }^{+}$] are shown as open squares.

in migraine with or without aura (MA/MO) indicating that the gene might also be a susceptibility locus for common forms of migraine (Todt et al., 2005). An overlap with epilepsy or seizures has been noted in about $15 \%$ of cases. Of note, two ATP1A2 mutations were identified in patients with AHC, such as the I589T mutation reported in an atypical case of AHC (Al-Bulushi et al., 2014), and T378M, which was found in two families, either correlated with FHM (Bassi et al., 2004) or with AHC (Swoboda et al., 2004). Other pathologies associated with ATP1A2 mutations were sensorineural hearing loss (V191M, Oh et al., 2015), basilar migraine (R548H, Ambrosini et al., 2005), benign familial infantile convulsions (BFIC; R689Q, Vanmolkot et al., 2003), generalized epilepsy with febrile seizures (GEFS+; G874S, Costa et al., 2014), pulmonary arterial hypertension (S940L, Montani et al., 2013) and reversible cerebral vasoconstriction (P979L Hermann et al., 2013).

Within the $\mathrm{Na}^{+}, \mathrm{K}^{+}$-ATPase crystal structure, more than $80 \%$ of mutations fall into four spatially distinct clusters, one around the catalytic $\mathrm{P}$ domain, one in a central region between $\mathrm{P}$ and TM domain, one within the extracellular-facing part of the TM domain, and one around the enzyme's C-terminus (Figure 2), which are all regions of critical importance for function. About $75 \%$ of the reported ATP1A2 mutations have been scrutinized for function at different levels of experimental sophistication (Supplementary Table 1).

\section{Functional Studies: Mildly and Severely Deleterious ATP1A2 Mutations}

Among the ATP1A2 mutations studied so far, some stand out because only mild consequences were observed (Supplementary Table 1). These include mutations at the enzyme's N-terminus, Y9N (SHM) and R51H (MO), which behaved similar to WT in biochemical studies on Sf9 cell membrane preparations (Swarts et al., 2013). A clue for the physiological consequences can be inferred from Song et al. (2006), who showed that ATP1A2 and ATP1A3 share an N-terminal targeting sequence 
within amino acids 1-90, which is apparently responsible for localization to jS/ER compartments in primary cultured mouse astrocytes. It remains to be clarified whether the N-terminal mutations of ATP1A2 interfere with targeting in order to decide whether or not these mutations are rare missense variants without pathogenic effects. The same accounts for E174K (MO), which was inconspicious in electrophysiological experiments on Xenopus oocytes and showed only mildly reduced activity in Sf9 cell preparations (Todt et al., 2005; Swarts et al., 2013), although the mutation inverts the charge of a highly conserved residue in the A domain, which might form a salt bridge with Lys432 in the $\mathrm{N}$ domain important for inter-domain interactions. Very similar observations were reported for the E902K (FHM) mutation, which showed electrophysiological properties like the WT enzyme (Spiller and Friedrich, 2014), but reduced ATPase activity and ouabain binding in Sf9 cell membrane preparations (Swarts et al., 2013). Also for K1003E (SHM+seizures) and R1007W (FHM), only mild consequences were reported from electrophysiology on Xenopus oocytes (Pisano et al., 2013; Spiller and Friedrich, 2014), despite the charge inverting/neutralizing effect.

At the other end of the functional spectrum, mutations that lead to a premature stop codon, a frame shift or a deletion/insertion are expected to cause severe functional disruptions. These include K95del (FHM \& epilepsy), F305del (SHM), R834X (FHM), del(K935-S940)insI (FHM), S966fs (FHM), L944del (SHM+focal seizures), and Y1009X (SHM), which all classify as familial or de novo mutations causing hemiplegic migraine, frequently with severe accompanying symptoms and, as far as functional studies are available, lead to complete loss of function and/or loss of plasma membrane targeting.

The remaining mutations, which entail loss or drastic reduction of activity, are depicted in Figure 7. These mutations mostly locate to the P domain and the extracellular TM domain cluster, with only a few others in the N domain (T415M, C515Y, $\mathrm{R} 548 \mathrm{H}$ ) and two in the central cluster (L764P, R937P). Mutation G301R (identified in two FHM kindreds) showed slightly reduced plasma membrane expression but no pumping activity in the Xenopus oocyte system, indicating reduced protein stability and complete loss-of-function (Tavraz et al., 2009). In HeLa cells, however, the mutant showed strongly reduced cell viability in ouabain survival assays, no plasma membrane expression and no protein detectable in Western blots (Santoro et al., 2011). The structure-destabilizing and functional disruption effect can be attributed to the insertion of a bulky, charged side chain within the center of the block of TM helices close to one of the common cation binding sites.

T376M (FHM) and T378N (FHM, AHC) affect two threonines in the ${ }^{373}$ SDKTGTLT ${ }^{380}$ motif around the intermediately phosphorylated Asp-374. Although the mutant proteins were expressed similar to the WT enzyme in Xenopus oocytes (T376M, Tavraz et al., 2008) and HeLa cells (T378N, Bassi et al., 2004), no pump activity or cell survival was observed. T415M (FHM) and C515Y (MA) affect two highly conserved residues at the periphery of the $\mathrm{N}$ domain, for which effects on function are difficult to infer. Nevertheless, the T415M mutant did not confer

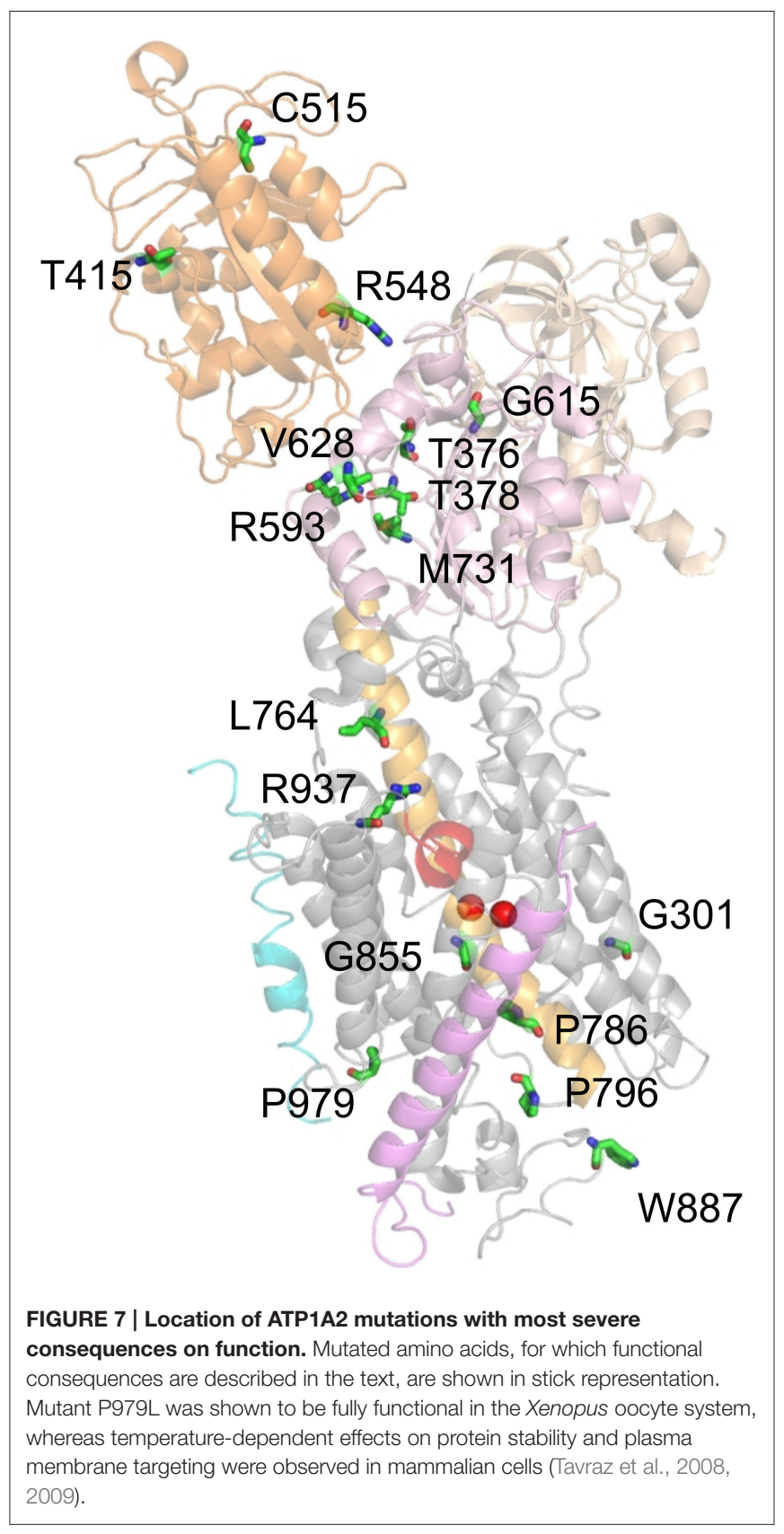

cell viability in ouabain survival assays despite normal protein level (Vanmolkot et al., 2007), and the C515Y mutation entailed strongly reduced pump currents and ATPase activity in Xenopus oocytes (Todt et al., 2005). Inter-domain interactions are also a critical concern for the R584H (basilar migraine/MA) and R548C (FHM) mutations, since Arg-548 likely forms a salt bridge with Glu-221 that stabilizes the interaction between the $\mathrm{A}$ and $\mathrm{N}$ domains in the $\mathrm{E}_{2} \mathrm{P}$ conformation, but probably forms another salt bridge to the $\beta$-phosphate of ATP. Although ATP affinity was not changed for mutant enzymes prepared from Sf9 cells, strongly reduced ATPase activities were observed (Swarts et al., 2013) indicating that the structure-coordinating effect of the salt bridge might be critical. 
Mutations R593W and V628M were both identified in FHM and showed strongly reduced cell viability in ouabain survival assays with normal protein level (Vanmolkot et al., 2006a), and R593W exhibited strongly reduced ATPase activity and reduced phosphoenzyme level in COS-1 cell membranes (Schack et al., 2012). Arg-593 is located at the border of the $P$ domain, directly after two prolines that form the hinge between the $\mathrm{P}$ and $\mathrm{N}$ domains. The residue is within hydrogen bonding distance of the backbone carbonyls of Gly-377 and Thr-378, which are located in the same loop as Asp-374 and Thr-376 indicating that the steric clash resulting from insertion of the tryptophan might disturb phosphorylation (Vanmolkot et al., 2006a; Schack et al., 2012). Val-628 resides in the $\mathrm{P}$ domain and is located at the border of the short, conserved P3 helix that together with the seven-stranded parallel $\beta$-sheet forms the typical Rossmann fold implicated in nucleotide binding suggesting an impact on catalytic activity (Schack et al., 2012). The G615R mutation, which was identified in FHM with particularly severe accompanying symptoms and in a patient with SHM, affects the glycine in the critical ${ }^{612} \mathrm{MVTG}^{616}$ structure motif in the $\mathrm{P}$ domain, which rationalizes that the mutation has been found to be deleterious for cell viability (Vanmolkot et al., 2006b).

The M731T mutation was functionally assessed by several groups (Capendeguy and Horisberger, 2004; Segall et al., 2005; Schack et al., 2012), with the most stringent study carried out on the human ATP1A2 enzyme (Schack et al., 2012), whereas the other two studied rat ATP1A2 (Segall et al., 2005) or ATP1A1 from Bufo marinus (Capendeguy and Horisberger, 2004). All studies converged on the notion of strongly reduced ATPase activity or loss of pump function. For efficient phosphorylation, the loop between $\beta$-sheet 6 and helix P7 of the Rossmann fold, in which Met-731 is located, has to be strained upon $\mathrm{Mg}^{2+}$ binding. Thus, the role of Met-731 may be to reduce the mobility of this loop to ensure the strain. Met-731 is also flanked by Arg-593 (see above), and the mutation might prevent proper bending of the $\mathrm{P}$ domain (Schack et al., 2012).

Mutations L764P and W887R were identified in the first report on FHM2 (De Fusco et al., 2003). L764P inserts a structurebreaking proline into the central helix TM5, which connects the phosphorylation site to the cation-binding pocket. The P786L (SHM) mutation also affects a residue on the extracellularlyoriented part of the TM5 helix. In accordance with the critical role of TM5, all studies investigating the effects of the TM5 mutations showed severe or complete loss of catalytic activity (Koenderink et al., 2005; Swarts et al., 2013) or cell survival (De Fusco et al., 2003; de Vries et al., 2007). The ${ }^{796}$ P796S $^{799}$ (FHM) mutation, which affects a proline within the conserved PLPL turn connecting TM5 and TM6, also did not support cell survival (Castro et al., 2008) or ATPase activity in Sf9 cell membranes (Weigand et al., 2014b).

The W887R mutant also did not confer cell survival (De Fusco et al., 2003), showed no pump currents (Capendeguy and Horisberger, 2004; Koenderink et al., 2005) and strongly reduced $\mathrm{Rb}^{+}$uptake, despite normal plasma membrane expression in Xenopus oocytes (Koenderink et al., 2005). From the structure, it is difficult to rationalize a loss of functional activity by this mutation. Trp-887 is located within the TM7-8 loop important for interaction with the $\beta$-subunit, but is not directly involved (Nyblom et al., 2013). If the interaction with the $\beta$-subunit were disrupted, a defect in membrane insertion and protein folding accompanying biosynthesis in the ER could be expected, with consequently reduced plasma membrane targeting, but this was not observed in the expression systems studied. Furthermore, the defective ouabain binding of the W887R mutant (Koenderink et al., 2005) is puzzling since Trp-887 was not implicated in ouabain binding. However, it was found in a mouse model for FHM2 that the mutant ATP1A2 protein was hardly detectable in the brain of homozygous ATP1A2(W887R/W887R) mutants and strongly reduced in ATP1A2(+/W887R) heterozygous mutants (Leo et al., 2011). In transfected HeLa cells, these authors also found profound protein loss, likely as the consequence of endoplasmic reticulum retention and subsequent proteasomal degradation. This finding contrasts with observations from the aforementioned study on transfected COS7 cells (De Fusco et al., 2003) indicating that it is important to avoid saturation effects in cell line used for transfection (Leo et al., 2011).

Mutation G855R (FHM+febrile seizures) did not confer cell survival (de Vries et al., 2009) or pump currents in the Xenopus oocyte system (Spiller and Friedrich, 2014), which in the latter system coincided with strongly reduced plasma membrane protein level. Gly-855 resides within TM7, a helix forming multiple contacts to the TM of the $\beta$-subunit (Nyblom et al., 2013), but Gly-855 is not directly involved in helix-helix contacts. However, due to the close packing of the helices, the introduction of a bulky side chain can indirectly affect the interaction with the $\beta$-subunit, which appears likely since the defective plasma membrane expression suggests improper folding and premature degradation.

Mutation R937P (FHM) did not show pump currents or $\mathrm{Rb}^{+}$uptake in an initial study on Xenopus oocytes (Tavraz et al., 2008), and no ATPase activity in Sf9 cell membranes (Weigand et al., 2014b). However, based on the knowledge about the involvement of Arg-937 in coordinating the $\alpha$-subunit's $C$ terminus, its link to $\mathrm{Na}^{+}$binding site III and the reported effects on $\mathrm{Na}^{+}$affinity (Toustrup-Jensen et al., 2009), it could be shown by electrophysiology that the mutation caused enhanced proton "leak" currents and a drastic negative shift of the $Q(V)$ curve from transient currents (Poulsen et al., 2010), in line with a drastically reduced apparent affinity for extracellular $\mathrm{Na}^{+}$. In effect, the R937P mutant still retains some essential properties of the $\mathrm{Na}^{+}$ pump, albeit with severely changed voltage dependence and enhanced proton leak, but the properties of the mutant's $\mathrm{Na}^{+}$, $\mathrm{K}^{+}$pump currents have still to be elucidated. R937P is so far the only FHM2 mutation that shows increased proton leak currents. Work by the Artigas and Gadsby labs showed that pumpmediated proton current is an intrinsic property of $\mathrm{Na}^{+}, \mathrm{K}^{+}$. ATPase (Mitchell et al., 2014; Vedovato and Gadsby, 2014) at physiological $\mathrm{K}^{+}$and $\mathrm{Na}^{+}$concentrations and resting potentials suggesting that this "hybrid" transporter function may well have been exploited by nature for some physiological purpose. It still remains to be established whether $\mathrm{Na}^{+}, \mathrm{K}^{+}$-ATPase-mediated proton uptake plays any physiological or pathological role (see Section Functional Properties of the $\mathrm{Na}^{+}, \mathrm{K}^{+}$-ATPase). 


\section{Mutation P979L Entails Temperature-Dependent Protein Instability and Mistargeting}

P979L is a particularly interesting mutation, which was reported to cause FHM2 in one of the earliest accounts on the genetic background of the disease (Jurkat-Rott et al., 2004), and, later, also in a case of SHM (Hermann et al., 2013). Comorbidities were serious, since the first report listed particularly severe attacks accompanied by recurrent coma and tonic-clonic seizures, whereas the SHM patient suffered from prolonged aura phase and severe reversible cerebral vasoconstriction. Within the crystal structure, Pro-979 is located within the TM9-10 loop and the protein backbone kink induced by the proline may be important for protein folding. However, when assayed by electrophysiology in Xenopus oocytes, all functional parameters were identical to those of the WT enzyme, with normal total and plasma membrane protein levels (Tavraz et al., 2008). However, in surface biotinylation assays on transfected HEK293FT cells, it was later found that the amount of P979L protein was strongly reduced, when the cells were incubated at $37^{\circ} \mathrm{C}$, but not upon cell incubation at $28^{\circ} \mathrm{C}$ (Tavraz et al., 2009). This discrepancy highlights the influence of the model cell system used. Xenopus oocytes are kept at $18-20^{\circ} \mathrm{C}$, a temperature range, which is advantageous for protein folding, whereas mammalian cells are grown at $37^{\circ} \mathrm{C}$, where protein instability might lead to misfolding and degradation. The situation is reminiscent of observations on the epithelial CFTR $\mathrm{Cl}^{-}$channel mutated in cystic fibrosis (CF). The most common CF mutation, the $\Delta \mathrm{F} 508$ deletion, leads to rapid degradation of the protein before exiting the ER in mammalian cells (kept at $37^{\circ} \mathrm{C}$ ), while the mutant protein could be functionally expressed in Xenopus oocytes. It could be shown that this effect is temperature-sensitive since protein degradation can be rescued at permissive temperature (Denning et al., 1992).

\section{SUMMARY AND PERSPECTIVES}

The detailed atomic-scale understanding of ion transport and catalysis of the $\mathrm{Na}^{+}, \mathrm{K}^{+}$-ATPase provided by the wealth of structural data together with the multi-modal efforts of numerous experimentalists have provided a rather stringent concept of the effects of migraine-associated ATP1A2 mutations on molecular function. While the spectrum of functional disruptions matches the complexity of the $\mathrm{Na}^{+}$pump's inner workings and the enzyme's even more complex integration into cellular signaling networks, the notion emerges that loss or change of any kind of functional parameter, including the seemingly subtle changes in voltage dependence could be of pathophysiological relevance. This is because for any of these alterations, pathophysiological conditions are conceivable that render these changes critical for controlling the excitability of electrically excitable tissues. Two seemingly self-evident but oversimplifying conclusions should be avoided: First, changes in $\mathrm{Na}^{+}$pump function brought about by disease-related mutations do not converge on a simple loss-of-function concept. While this is certainly true for mutations abolishing $\mathrm{Na}^{+}, \mathrm{K}^{+}$pumping, a change in voltage dependence may entail loss-of-function in a particular voltage range, but gain-of-function in another. Furthermore, given the controversy about whether proton leak currents are part of the $\mathrm{Na}^{+}$pump's physiological spectrum of functions, both, reduced proton leaks (loss-of-function, as discussed for the E815K mutation in ATP1A3 in AHC) as well as increased proton leaks (gain-of-function, as discussed for somatic ATP1A1 mutations in APA) could be causative for one or the other pathophysiological state. Second, the CSD phenomenon is not simply the consequence of either cortical hypo- or hyperexcitability. Rather, it emerges that the reduced ability to dynamically maintain the cortical excitatory/inhibitory balance and the failure to prevent excessive increases in cortical excitation mechanistically explain the abnormal sensory processing in migraineurs.

While it is commonly accepted that functional changes in FHM-related genes including those in ATP1A2 converge on CSD as the neurophysiological correlate of migraine aura, the link to the most disabling condition of the disease, the throbbing migraine pain, is still a matter of debate. Currently, the view emerges that CSD can cause sustained activation of meningeal nociceptors and central trigeminovascular neurons to initiate the headache mechanisms in a process termed sterile meningeal inflammation. Moreover, the physiological control parameters discriminating between the propagation speeds of rapid (epileptic seizures) or slow (CSD) waves of cortical hyperexcitation need to be investigated in more detail to identify critical network parameters for or by in silico modeling of excitable biological matter. In this context, knowing the parameters of dysfunction of mutated ion pumps and channels of the CNS may help to identify the elements that count. The remarkable progress achieved by computational neuroscientists who have just recently put forward the idea that cell volume regulation is critical for determining whether an excitable tissue may evolve into seizures or spreading depression, provides novel hypotheses to be tested by experiment. This should encourage synergistic, cross-disciplinary collaborations between researchers studying excitable matter on the clinical, in vivo, in vitro, and in silico level.

In order to classify an ATP1A2 mutation as causative for a disease, at least the simplest test should be performed, an ouabain survival assay in mammalian cells. For the assessment of enzyme catalysis, biochemical studies on protein preparations from mammalian cell lines or Sf9 cells provide exhaustive tools of characterization. However, elucidation of the most essential physiological function, electrogenic $\mathrm{Na}^{+}, \mathrm{K}^{+}$transport, requires dedicated electrophysiological assays on intact cells. For this purpose, the Xenopus oocyte expression system is a versatile tool, since it permits electrophysiology as well as cation uptake assays, and some means of fundamental protein biochemistry. Whereas electrophysiology on oocytes is indispensible for researchers interested in understanding $\mathrm{Na}^{+}$pump function in molecular detail, the Xenopus system is less physiological when it comes to effects on protein expression, stability or targeting, as the example of the P979L mutant and others noted in this work have shown. Thus, as a rule of thumb, the observed functional consequences should ideally be cross-checked in at least two different cell systems in order to avoid both false-positive and false-negative conclusions. 


\section{AUTHOR CONTRIBUTIONS}

TF and NT performed literature searches, TF prepared figures and all authors wrote the manuscript.

\section{ACKNOWLEDGMENTS}

Financial support by the German Research Foundation (DFG, Cluster of Excellence Unicat, to TF and NT) and by the European

\section{REFERENCES}

Albers, R. W. (1967). Biochemical aspects of active transport. Ann. Rev. Biochem. 36, 727-756. doi: 10.1146/annurev.bi.36.070167.003455

Al-Bulushi, B., Al-Hashem, A., and Tabarki, B. (2014). A wide clinical phenotype spectrum in patients with ATP1A2 mutations. J. Child Neurol. 29, 265-268. doi: $10.1177 / 0883073813504623$

Ambrosini, A., D’Onofrio, M., Grieco, G. S., Di Mambro, A., Montagna, G., Fortini, D., et al. (2005). Familial basilar migraine associated with a new mutation in the ATP1A2 gene. Neurology 65, 1826-1828. doi: 10.1212/01.wnl.0000187072.71931.c0

Apell, H. J., and Karlish, S. J. (2001). Functional properties of Na,K-ATPase, and their structural implications, as detected with biophysical techniques. J. Membr. Biol. 180, 1-9. doi: 10.1007/s002320010053

Axelsen, K. B., and Palmgren, M. G. (1998). Evolution of substrate specificities in the P-type ATPase superfamily. J. Mol. Evol. 46, 84-101. doi: 10.1007/PL00006286

Azizan, E. A., Poulsen, H., Tuluc, P., Zhou, J., Clausen, M. V., Lieb, A., et al. (2013). Somatic mutations in ATP1A1 and CACNA1D underlie a common subtype of adrenal hypertension. Nat. Genet. 45, 1055-1060. doi: 10.1038/ng.2716

Ba, A. M., Guiou, M., Pouratian, N., Muthialu, A., Rex, D. E., Cannestra, A. F., et al. (2002). Multiwavelength optical intrinsic signal imaging of cortical spreading depression. J. Neurophysiol. 88, 2726-2735. doi: 10.1152/jn.00729.2001

Bassi, M. T., Bresolin, N., Tonelli, A., Nazos, K., Crippa, F., Baschirotto, C., et al. (2004). A novel mutation in the ATP1A2 gene causes alternating hemiplegia of childhood. J. Med. Genet. 41, 621-628. doi: 10.1136/jmg.2003.017863

Beuschlein, F., Boulkroun, S., Osswald, A., Wieland, T., Nielsen, H. N., Lichtenauer, U. D., et al. (2013). Somatic mutations in ATP1A1 and ATP2B3 lead to aldosterone-producing adenomas and secondary hypertension. Nat. Genet. 45, 441-442. doi: 10.1038/ng.2550

Blanco, G., Melton, R. J., Sanchez, G., and Mercer, R. W. (1999). Functional characterization of a testes-specific alpha-subunit isoform of the sodium/potassium adenosinetriphosphatase. Biochemistry 38, 13661-13669. doi: $10.1021 /$ bi991207b

Blaustein, M. P., and Golovina, V. A. (2001). Structural complexity and functional diversity of endoplasmic reticulum $\mathrm{Ca}^{2+}$ stores. Trends Neurosci. 24, 602-608. doi: 10.1016/S0166-2236(00)01891-9

Capendeguy, O., and Horisberger, J. D. (2004). Functional effects of $\mathrm{Na}^{+}, \mathrm{K}^{+}$ATPase gene mutations linked to familial hemiplegic migraine. Neuromolecular Med. 6, 105-116. doi: 10.1385/NMM:6:2-3:105

Castro, M. J., Nunes, B., de Vries, B., Lemos, C., Vanmolkot, K. R., van den Heuvel, J. J., et al. (2008). Two novel functional mutations in the $\mathrm{Na}^{+}, \mathrm{K}^{+}$ATPase alpha2-subunit ATP1A2 gene in patients with familial hemiplegic migraine and associated neurological phenotypes. Clin. Genet. 73, 37-43. doi: 10.1111/j.1399-0004.2007.00918.x

Chesler, M. (2003). Regulation and modulation of $\mathrm{pH}$ in the brain. Physiol. Rev. 83, 1183-1221. doi: 10.1152/physrev.00010.2003

Cholet, N., Pellerin, L., Magistretti, P. J., and Hamel, E. (2002). Similar perisynaptic glial localization for the $\mathrm{Na}^{+}, \mathrm{K}^{+}$-ATPase alpha2-subunit and the glutamate transporters GLAST and GLT-1 in the rat somatosensory cortex. Cereb. Cortex 12, 515-525. doi: $10.1093 /$ cercor/12.5.515

Clarke, R. J. (2009). Mechanism of allosteric effects of ATP on the kinetics of P-type ATPases. Eur. Biophys. J. 39, 3-17. doi: 10.1007/s00249-009-0407-3
Cooperation in Science and Technology (COST action MP1205, to CJ) is gratefully acknowledged.

\section{SUPPLEMENTARY MATERIAL}

The Supplementary Material for this article can be found online at: http://journal.frontiersin.org/article/10.3389/fphys. 2016.00239

Cohen, E., Goldshleger, R., Shainskaya, A., Tal, D. M., Ebel, C., le Maire, M. et al. (2005). Purification of $\mathrm{Na}^{+}, \mathrm{K}^{+}$-ATPase expressed in Pichia pastoris reveals an essential role of phospholipid-protein interactions. J. Biol. Chem. 280, 16610-16608. doi: 10.1074/jbc.M414290200

Costa, C., Prontera, P., Sarchielli, P., Tonelli, A., Bassi, M. T., Cupini, L. M., et al. (2014). A novel ATP1A2 gene mutation in familial hemiplegic migraine and epilepsy. Cephalalgia 34, 68-72. doi: 10.1177/0333102413498941

Crambert, G., Hasler, U., Beggah, A. T., Yu, C., Modyanov, N. N., Horisberger, J. D., et al. (2000). Transport and pharmacological properties of nine different human Na, K-ATPase isozymes. J. Biol. Chem. 275, 1976-1986. doi: $10.1074 /$ jbc.275.3.1976

Cressman, J. R. Jr., Ullah, G., Ziburkus, J., Schiff, S. J., and Barreto, E. (2009). The influence of sodium and potassium dynamics on excitability, seizures, and the stability of persistent states: i single neuron dynamics. J. Comput. Neurosci. 26, 159-170. doi: 10.1007/s10827-008-0132-4

Dahlem, M. A., Kurths, J., Ferrari, M. D., Aihara, K., Scheffer, M., and May, A. (2014). Understanding migraine using dynamic network biomarkers. Cephalalgia 35, 627-630. doi: 10.1177/0333102414550108

Dahlem, M. A., Rode, S., May, A., Fujiwara, N., Hirata, Y., Aihara, K., et al. (2013). Towards dynamical network biomarkers in neuromodulation of episodic migraine. Transl. Neurosci. 4, 282-294. doi: 10.2478/s13380-013-0127-0

de Carvalho Aguiar, P., Sweadner, K. J., Penniston, J. T., Zaremba, J., Liu, L., Caton, M., et al. (2004). Mutations in the $\mathrm{Na}^{+} / \mathrm{K}^{+}$-ATPase alpha3 gene ATP1A3 are associated with rapid-onset dystonia parkinsonism. Neuron 43, 169-175. doi: 10.1016/j.neuron.2004.06.028

De Fusco, M., Marconi, R., Silvestri, L., Atorino, L., Rampoldi, L., Morgante, L., et al. (2003). Haploinsufficiency of ATP1A2 encoding the $\mathrm{Na}^{+} / \mathrm{K}^{+}$pump alpha2-subunit associated with familial hemiplegic migraine type 2. Nat. Genet. 33, 192-196. doi: 10.1038/ng1081

Denning, G. M., Anderson, M. P., Amara, J. F., Marshall, J., Smith, A. E., and Welsh, M. J. (1992). Processing of mutant cystic fibrosis transmembrane conductance regulator is temperature-sensitive. Nature 358, 761-764. doi: 10.1038/358761a0

de Vries, B., Freilinger, T., Vanmolkot, K. R., Koenderink, J. B., Stam, A. H., Terwindt, G. M., et al. (2007). Systematic analysis of three FHM genes in 39 sporadic patients with hemiplegic migraine. Neurology 69, 2170-2176. doi: 10.1212/01.wnl.0000295670.01629.5a

de Vries, B., Stam, A. H., Kirkpatrick, M., Vanmolkot, K. R., Koenderink, J. B., van den Heuvel, J. J., et al. (2009). Familial hemiplegic migraine is associated with febrile seizures in an FHM2 family with a novel de novo ATP1A2 mutation. Epilepsia 50, 2503-2504. doi: 10.1111/j.1528-1167.2009.02186.x

Dichgans, M., Freilinger, T., Eckstein, G., Babini, E., Lorenz-Depiereux, B., Biskup, S., et al. (2005). Mutation in the neuronal voltage-gated sodium channel SCN1A in familial hemiplegic migraine. Lancet 366, 371-377. doi: 10.1016/S01406736(05)66786-4

DiFranco, M., Hakimjavadi, H., Lingrel, J. B., and Heiny, J. A. (2015). Na,K-ATPase alpha2 activity in mammalian skeletal muscle T-tubules is acutely stimulated by extracellular $\mathrm{K}^{+}$. J. Gen. Physiol. 146, 281-294. doi: 10.1085/jgp.2015 11407

Donnet, C., Arystarkhova, E., and Sweadner, K. J. (2001). Thermal denaturation of the $\mathrm{Na}, \mathrm{K}$-ATPase provides evidence for alpha-alpha oligomeric interaction and gamma subunit association with the C-terminal domain. J. Biol. Chem. 276, 7357-7365. doi: 10.1074/jbc.M009131200 
Efthymiadis, A., Rettinger, J., and Schwarz, W. (1993). Inward-directed current generated by the $\mathrm{Na}^{+}, \mathrm{K}^{+}$pump in $\mathrm{Na}^{+}$- and $\mathrm{K}^{+}$-free medium. Cell Biol. Int. 17, 1107-1116. doi: 10.1006/cbir.1993.1043

Eikermann-Haerter, K., Dilekoz, E., Kudo, C., Savitz, S. I., Waeber, C., Baum, M. J., et al. (2009). Genetic and hormonal factors modulate spreading depression and transient hemiparesis in mouse models of familial hemiplegic migraine type 1. J. Clin. Invest. 119, 99-109. doi: 10.1172/JCI36059

Fendler, K., Grell, E., Haubs, M., and Bamberg, E. (1985). Pump currents generated by the purified $\mathrm{Na}^{+} \mathrm{K}^{+}$-ATPase from kidney on black lipid membranes. EMBO J. 4, 3079-3085.

Forbush, B. III., Kaplan, J. H., and Hoffman, J. F. (1978). Characterization of a new photoaffinity derivative of ouabain: labeling of the large polypeptide and of a proteolipid component of the Na, K-ATPase. Biochemistry 17, 3667-3676. doi: $10.1021 / \mathrm{bi00610a037}$

Gadsby, D. C. (2009). Ion channels versus ion pumps: the principal difference, in principle. Nat. Rev. Mol. Cell Biol. 10, 344-352. doi: 10.1038/nrm2668

Gadsby, D. C., Kimura, J., and Noma, A. (1985). Voltage dependence of $\mathrm{Na} / \mathrm{K}$ pump current in isolated heart cells. Nature 315, 63-65. doi: 10.1038/31 $5063 \mathrm{a} 0$

Gadsby, D. C., and Nakao, M. (1989). Steady-state current-voltage relationship of the Na/K pump in guinea pig ventricular myocytes. J. Gen. Physiol. 94, 511-537. doi: $10.1085 /$ jgp.94.3.511

Gadsby, D. C., Rakowski, R. F., and De Weer, P. (1993). Extracellular access to the Na,K pump: pathway similar to ion channel. Science 260, 100-103. doi: $10.1126 /$ science.7682009

Garty, H., and Karlish, S. J. (2006). Role of FXYD proteins in ion transport. Annu. Rev. Physiol. 68, 431-459. doi: 10.1146/annurev.physiol.68.040104.131852

Geering, K. (2006). FXYD proteins: new regulators of Na-K-ATPase. Am. J. Physiol. Renal Physiol. 290, F241-F250. doi: 10.1152/ajprenal.00126.2005

Glorioso, N., Filigheddu, F., Troffa, C., Soro, A., Parpaglia, P. P., Tsikoudakis, A., et al. (2001). Interaction of alpha(1)-Na,K-ATPase and $\mathrm{Na}, \mathrm{K}, 2 \mathrm{Cl}$ cotransporter genes in human essential hypertension. Hypertension 38, 204-209. doi: 10.1161/01.HYP.38.2.204

Glynn, I. M. (1985). "The $\mathrm{Na}^{+}, \mathrm{K}^{+}$-transporting adenosine triphosphatase," in The Enzymes of Biological Membranes, ed A. Martonosi (New York, NY; London: Plenum Publishing Corp), 35-114.

Golovina, V. A., Song, H., James, P. F., Lingrel, J. B., and Blaustein, M. P. (2003). $\mathrm{Na}^{+}$pump alpha2-subunit expression modulates $\mathrm{Ca}^{2+}$ signaling. Am. J. Physiol. Cell Physiol. 284, C475-C486. doi: 10.1152/ajpcell.00383.2002

Han, F., Tucker, A. L., Lingrel, J. B., Despa, S., and Bers, D. M. (2009). Extracellular potassium dependence of the $\mathrm{Na}^{+}-\mathrm{K}^{+}$-ATPase in cardiac myocytes: isoform specificity and effect of phospholemman. Am. J. Physiol. Cell Physiol. 297, C699-C705. doi: 10.1152/ajpcell.00063.2009

He, S., Shelly, D. A., Moseley, A. E., James, P. F., James, J. H., Paul, R. J., et al. (2001). The alpha(1)- and alpha(2)-isoforms of Na-K-ATPase play different roles in skeletal muscle contractility. Am. J. Physiol. Regul. Integr. Comp. Physiol. 281, R917-R925.

Heinzen, E. L., Swoboda, K. J., Hitomi, Y., Gurrieri, F., Nicole, S., de Vries, B., et al. (2012). De novo mutations in ATP1A3 cause alternating hemiplegia of childhood. Nat. Genet. 44, 1030-1034. doi: 10.1038/ng.2358

Hermann, A., Engelandt, K., Rautenstrauss, B., Reichmann, H., and Jacobasch, E. (2013). Hemiplegic migraine with reversible cerebral vasoconstriction caused by ATP1A2 mutations. J. Neurol. 260, 2172-2174. doi: 10.1007/s00415-0137010-3

Hilbers, F., Kopec, W., Isaksen, T. J., Holm, T. H., Lykke-Hartmann, K., Nissen, P., et al. (2016). Tuning of the Na,K-ATPase by the beta subunit. Sci. Rep. 6:20442. doi: $10.1038 /$ srep20442

Hilgemann, D. W. (1994). Channel-like function of the Na,K pump probed at microsecond resolution in giant membrane patches. Science 263, 1429-1432. doi: $10.1126 /$ science. 8128223

Holmgren, M., and Rakowski, R. F. (2006). Charge translocation by the $\mathrm{Na}+\mathrm{K}+$ pump under $\mathrm{Na}+\mathrm{Na}+$ exchange conditions: intracellular $\mathrm{Na}+$ dependence. Biophys. J. 90, 1607-1616. doi: 10.1529/biophysj.105.072942

Holmgren, M., Wagg, J., Bezanilla, F., Rakowski, R. F., De Weer, P., and Gadsby, D. C. (2000). Three distinct and sequential steps in the release of sodium ions by the $\mathrm{Na}^{+} / \mathrm{K}^{+}$-ATPase. Nature 403, 898-901. doi: 10.1038/35002599

James, P. F., Grupp, I. L., Grupp, G., Woo, A. L., Askew, G. R., Croyle, M. L., et al. (1999). Identification of a specific role for the Na,K-ATPase alpha 2 isoform as a regulator of calcium in the heart. Mol. Cell 3, 555-563. doi: 10.1016/S10972765(00)80349-4

Jaunin, P., Jaisser, F., Beggah, A. T., Takeyasu, K., Mangeat, P., Rossier, B. C., et al. (1993). Role of the transmembrane and extracytoplasmic domain of beta subunits in subunit assembly, intracellular transport, and functional expression of Na,K-pumps. J. Cell Biol. 123, 1751-1759. doi: 10.1083/jcb.123.6.1751

Juhaszova, M., and Blaustein, M. P. (1997). $\mathrm{Na}^{+}$pump low and high ouabain affinity alpha subunit isoforms are differently distributed in cells. Proc. Natl. Acad. Sci. U.S.A. 94, 1800-1805. doi: 10.1073/pnas.94.5.1800

Jurkat-Rott, K., Freilinger, T., Dreier, J. P., Herzog, J., Göbel, H., Petzold, G. C., et al. (2004). Variability of familial hemiplegic migraine with novel A1A2 $\mathrm{Na}^{+} / \mathrm{K}^{+}$-ATPase variants. Neurology 62, 1857-1861. doi: 10.1212/01.WNL.0000127310.11526.FD

Kanai, R., Ogawa, H., Vilsen, B., Cornelius, F., and Toyoshima, C. (2013). Crystal structure of a Na${ }^{+}$-bound $\mathrm{Na}^{+}, \mathrm{K}^{+}$-ATPase preceding the E1P state. Nature 502, 201-206. doi: 10.1038/nature12578

Kaplan, J. H. (2002). Biochemistry of the Na,K-ATPase. Annu. Rev. Biochem. 71, 511-535. doi: 10.1146/annurev.biochem.71.102201.141218

Katz, A., Lifshitz, Y., Bab-Dinitz, E., Kapri-Pardes, E., Goldshleger, R., Tal, D. M., et al. (2010). Selectivity of digitalis glycosides for isoforms of human Na,K-ATPase. J. Biol. Chem. 285, 19582-19592. doi: 10.1074/jbc.M110. 119248

Koenderink, J. B., Zifarelli, G., Qiu, L. Y., Schwarz, W., De Pont, J. J., Bamberg, E., et al. (2005). Na,K-ATPase mutations in familial hemiplegic migraine lead to functional inactivation. Biochim. Biophys. Acta 1669, 61-68. doi: 10.1016/j.bbamem.2005.01.003

Koch, M. C., Steinmeyer, K., Lorenz, C., Ricker, K., Wolf, F., Otto, M., et al. (1992). The skeletal muscle chloride channel in dominant and recessive human myotonia. Science 257, 797-800. doi: 10.1126/science.1379744

Larsen, B. R., Assentoft, M., Cotrina, M. L., Hua, S. Z., Nedergaard, M., Kaila, K., et al. (2014). Contributions of the $\mathrm{Na}^{+} / \mathrm{K}^{+}$-ATPase, NKCC1, and Kir4.1 to hippocampal $\mathrm{K}^{+}$clearance and volume responses. Glia $62,608-622$. doi: $10.1002 /$ glia.22629

Läuger, P. (1979). A channel mechanism for electrogenic ion pumps. Biochim. Biophys. Acta 552, 143-161. doi: 10.1016/0005-2736(79)90253-0

Leão, A. A. P. (1944). Spreading depression of activity in the cerebral cortex. J. Neurophysiol. 7, 359-390.

Lencesova, L., O’Neill, A., Resneck, W. G., Bloch, R. J., and Blaustein, M. P. (2004). Plasma membrane-cytoskeleton-endoplasmic reticulum complexes in neurons and astrocytes. J. Biol. Chem. 279, 2885-2893. doi: 10.1074/jbc.M310365200

Leo, L., Gherardini, L., Barone, V., De Fusco, M., Pietrobon, D., Pizzorusso, T., et al. (2011). Increased susceptibility to cortical spreading depression in the mouse model of familial hemiplegic migraine type 2. PLoS Genet. 7:e1002129. doi: 10.1371/journal.pgen.1002129

Li, C., Geering, K., and Horisberger, J. D. (2006). The third sodium binding site of $\mathrm{Na}, \mathrm{K}-\mathrm{ATPase}$ is functionally linked to acidic $\mathrm{pH}$-activated inward current. J. Membr. Biol. 213, 1-9. doi: 10.1007/s00232-006-0035-0

Li, M., Jazayeri, D., Corry, B., McSweeney, K. M., Heinzen, E. L., Goldstein, D. B., et al. (2015). A functional correlate of severity in alternating hemiplegia of childhood. Neurobiol. Dis. 77, 88-93. doi: 10.1016/j.nbd.2015. 02.002

Lingrel, J. B. (2010). The physiological significance of the cardiotonic steroid/ouabain-binding site of the Na,K-ATPase. Annu. Rev. Physiol. 72, 395-412. doi: 10.1146/annurev-physiol-021909-135725

$\mathrm{Lu}$, J. T., and Kass, R. S. (2010). Recent progress in congenital long QT syndrome. Curr. Opin. Cardiol. 25, 216-221. doi: 10.1097/HCO.0b013e32833846b3

Meier, S., Tavraz, N. N., Dürr, K. L., and Friedrich, T. (2010). Hyperpolarizationactivated inward leakage currents caused by deletion or mutation of carboxyterminal tyrosines of the $\mathrm{Na}^{+} / \mathrm{K}^{+}$-ATPase a-subunit. J. Gen. Physiol. 135 115-134. doi: 10.1085/jgp.200910301

Meij, I. C., Koenderink, J. B., van Bokhoven, H., Assink, K. F., Groenestege, W. T., de Pont, J. J., et al. (2000). Dominant isolated renal magnesium loss is caused by misrouting of the $\mathrm{Na}^{+}, \mathrm{K}^{+}$-ATPase gamma-subunit. Nat. Genet. 26, 265-256. doi: $10.1038 / 81543$

Mercer, R. W., Biemesderfer, D., Bliss, D. P. Jr., Collins, J. H., and Forbush, B. III. (1993). Molecular cloning and immunological characterization of the gamma polypeptide, a small protein associated with the Na,K-ATPase. J. Cell Biol. 121, 579-586. doi: $10.1083 /$ jcb.121.3.579 
Mitchell, T. J., Zugarramurdi, C., Olivera, J. F., Gatto, C., and Artigas, P. (2014). Sodium and proton effects on inward proton transport through $\mathrm{Na} / \mathrm{K}$ pumps. Biophys. J. 106, 2555-2565. doi: 10.1016/j.bpj.2014.04.053

Mohler, P. J., Davis, J. Q., and Bennett, V. (2005). Ankyrin-B coordinates the $\mathrm{Na} / \mathrm{K}$ ATPase, $\mathrm{Na} / \mathrm{Ca}$ exchanger, and InsP3 receptor in a cardiac $\mathrm{T}$ tubule/SR microdomain. PLoS Biol. 3:e423. doi: 10.1371/journal.pbio.0 030423

Montani, D., Girerd, B., Gunther, S., Riant, F., Tournier-Lasserve, E., Magy, L., et al. (2013). Pulmonary arterial hypertension in familial hemiplegic migraine with ATP1A2 channelopathy. Eur. Respir. J. 43, 641-643. doi: $10.1183 / 09031936.00147013$

Morth, J. P., Pedersen, B. P., Toustrup-Jensen, M. S., Sørensen, T. L., Petersen, J., Andersen, J. P., et al. (2007). Crystal structure of the sodium-potassium pump. Nature 450, 1043-1049. doi: 10.1038/nature06419

Moseley, A. E., Lieske, S. P., Wetzel, R. K., James, P. F., He, S., Shelly, D. A., et al. (2003). The Na,K-ATPase alpha 2 isoform is expressed in neurons, and its absence disrupts neuronal activity in newborn mice. J. Biol. Chem. 278, 5317-5324. doi: 10.1074/jbc.M211315200

Moseley, A. E., Williams, M. T., Schaefer, T. L., Bohanan, C. S., Neumann, J. C., Behbehani, M. M., et al. (2007). Deficiency in Na,K-ATPase alpha isoform genes alters spatial learning, motor activity, and anxiety in mice. J. Neurosci. 27, 616-626. doi: 10.1523/JNEUROSCI.4464-06.2007

Moskowitz, M. A., Bolay, H., and Dalkara, T. (2004). Deciphering migraine mechanisms: clues from familial hemiplegic migraine genotypes. Ann. Neurol. 55, 276-280. doi: 10.1002/ana.20035

Nakao, M., and Gadsby, D. C. (1986). Voltage dependence of Na translocation by the $\mathrm{Na} / \mathrm{K}$ pump. Nature 323, 628-630. doi: 10.1038/323628a0

Nakao, M., and Gadsby, D. C. (1989). [Na] and [K] dependence of the Na/K pump current-voltage relationship in guinea pig ventricular myocytes. J. Gen. Physiol. 94, 539-565. doi: 10.1085 /jgp.94.3.539

Nyblom, M., Poulsen, H., Gourdon, P., Reinhard, L., Andersson, M., Lindahl, E., et al. (2013). Crystal structure of $\mathrm{Na}^{+}, \mathrm{K}^{+}$-ATPase in the $\mathrm{Na}^{+}$-bound state. Science 342, 123-127. doi: 10.1126/science. 1243352

Ogawa, H., Shinoda, T., Cornelius, F., and Toyoshima, C. (2009). Crystal structure of the sodium-potassium pump $\mathrm{Na}^{+}, \mathrm{K}^{+}$-ATPase with bound potassium and ouabain. Proc. Natl. Acad. Sci. U.S.A. 106, 13742-13747. doi: 10.1073/pnas.0907054106

Oh, S. K., Baek, J. I., Weigand, K. M., Venselaar, H., Swarts, H. G., Park, S. H., et al. (2015). A missense variant of the ATP1A2 gene is associated with a novel phenotype of progressive sensorineural hearing loss associated with migraine. Eur. J. Hum. Genet. 23, 639-645. doi: 10.1038/ejhg.2014.154

Olesen, C., Picard, M., Winther, A. M., Gyrup, C., Morth, J. P., Oxvig, C., et al. (2007). The structural basis of calcium transport by the calcium pump. Nature 450, 1036-1042. doi: 10.1038/nature06418

Ophoff, R. A., Terwindt, G. M., Vergouwe, M. N., van Eijk, R., Oefner, P. J., Hoffman, S. M., et al. (1996). Familial hemiplegic migraine and episodic ataxia type- 2 are caused by mutations in the $\mathrm{Ca}^{2+}$ channel gene CACNL1A4. Cell 87, 543-552. doi: 10.1016/S0092-8674(00)81373-2

Paulsen, P. A., Jurkowski, W., Apostolov, R., Lindahl, E., Nissen, P., and Poulsen, H. (2012). The C-terminal cavity of the Na,K-ATPase analyzed by docking and electrophysiology. Mol. Membr. Biol. 30, 195-205. doi: $10.3109 / 09687688.2012 .713520$

Pedersen, T. H., Riisager, A., de Paoli, F. V., Chen, T. Y., and Nielsen, O. B. (2016). Role of physiological ClC-1 $\mathrm{Cl}^{-}$ion channel regulation for the excitability and function of working skeletal muscle. J. Gen. Physiol. 147, 291-308. doi: 10.1085/jgp.201611582

Perea, G., Navarrete, M., and Araque, A. (2009). Tripartite synapses: astrocytes process and control synaptic information. Trends Neurosci. 32, 421-431. doi: 10.1016/j.tins.2009.05.001

Pietrobon, D. (2007). Familial hemiplegic migraine. Neurotherapeutics 4, 274-284. doi: $10.1016 /$ j.nurt.2007.01.008

Pietrobon, D., and Moskowitz, M. A. (2013). Pathophysiology of migraine. Annu. Rev. Physiol. 75, 365-391. doi: 10.1146/annurev-physiol-030212-183717

Pietrobon, D., and Moskowitz, M. A. (2014). Chaos and commotion in the wake of cortical spreading depression and spreading depolarizations. Nat. Rev. Neurosci. 15, 379-393. doi: 10.1038/nrn3770

Pietrobon, D., and Striessnig, J. (2003). Neurobiology of migraine. Nat. Rev. Neurosci. 4, 386-398. doi: 10.1038/nrn1102
Pintschovius, J., Fendler, K., and Bamberg, E. (1999). Charge translocation by the $\mathrm{Na}^{+} / \mathrm{K}^{+}$-ATPase investigated on solid supported membranes: cytoplasmic cation binding and release. Biophys. J. 76, 827-836. doi: 10.1016/S00063495(99)77246-2

Pisano, T., Spiller, S., Mei, D., Guerrini, R., Cianchetti, C., Friedrich, T., et al. (2013). Functional characterization of a novel C-terminal ATP1A2 mutation causing hemiplegic migraine and epilepsy. Cephalalgia 33, 1302-1310. doi: $10.1177 / 0333102413495116$

Post, R. L., Hegyvary, C., and Kume, S. (1972). Activation by adenosine triphosphate in the phosphorylation kinetics of sodium and potassium transporting adenosine triphosphatase. J. Biol. Chem. 247, 6530-6540.

Poulsen, H., Khandelia, H., Morth, J. P., Bublitz, M., Mouritsen, O. G., Egebjerg, J., et al. (2010). Neurological disease mutations compromise a C-terminal ion pathway in the $\mathrm{Na}^{+} / \mathrm{K}^{+}$-ATPase. Nature 467, 99-102. doi: 10.1038/nature 09309

Price, E. M., and Lingrel, J. B. (1988). Structure-function relationships in the Na,KATPase alpha subunit: site-directed mutagenesis of glutamine-111 to arginine and asparagine-122 to aspartic acid generates a ouabain-resistant enzyme. Biochemistry 27, 8400-8408. doi: 10.1021/bi00422a016

Radzyukevich, T. L., Moseley, A. E., Shelly, D. A., Redden, G. A., Behbehani, M. M., Lingrel, J. B., et al. (2004). The $\mathrm{Na}^{+}-\mathrm{K}^{+}$-ATPase alpha2-subunit isoform modulates contractility in the perinatal mouse diaphragm. Am. J. Physiol. Cell. Physiol. 287, C1300-C1310. doi: 10.1152/ajpcell.00231.2004

Radzyukevich, T. L., Neumann, J. C., Rindler, T. N., Oshiro, N., Goldhamer, D. J., Lingrel, J. B., et al. (2013). Tissue-specific role of the Na,KATPase alpha2 isozyme in skeletal muscle. J. Biol. Chem. 288, 1226-1237. doi: $10.1074 /$ jbc.M112.424663

Rakowski, R. F. (1993). Charge movement by the Na/K pump in Xenopus oocytes. J. Gen. Physiol. 101, 117-144. doi: 10.1085/jgp.101.1.117

Rakowski, R. F., Gadsby, D. C., and De Weer, P. (1997). Voltage dependence of the Na/K pump. J. Membr. Biol. 155, 105-112. doi: 10.1007/s002329 900162

Rakowski, R. F., Vasilets, L. A., LaTona, J., and Schwarz, W. (1991). A negative slope in the current-voltage relationship of the $\mathrm{Na}^{+} / \mathrm{K}^{+}$pump in Xenopus oocytes produced by reduction of external $\left[\mathrm{K}^{+}\right]$. J. Membr. Biol. 121, 177-187. doi: $10.1007 / \mathrm{BF} 01870531$

Rettinger, J. (1996). Characteristics of $\mathrm{Na}^{+} / \mathrm{K}^{+}$-ATPase mediated proton current in $\mathrm{Na}^{+}$- and $\mathrm{K}^{+}$-free extracellular solutions. Indications for kinetic similarities between $\mathrm{H}^{+} / \mathrm{K}^{+}$-ATPase and $\mathrm{Na}^{+} / \mathrm{K}^{+}$-ATPase. Biochim. Biophys. Acta 1282 , 207-215. doi: 10.1016/0005-2736(96)00057-0

Riant, F., Roze, E., Barbance, C., Meneret, A., Guyant-Marechal, L., Lucas, C., et al. (2012). PRRT2 mutations cause hemiplegic migraine. Neurology 79, 2122-2124. doi: 10.1212/WNL.0b013e3182752cb8

Rindler, T. N., Dostanic, I., Lasko, V. M., Nieman, M. L., Neumann, J. C., Lorenz, J. N., et al. (2011). Knockout of the Na,K-ATPase alpha(2)-isoform in the cardiovascular system does not alter basal blood pressure but prevents ACTHinduced hypertension. Am. J. Physiol. Heart. Circ. Physiol. 301, H1396-H1404. doi: 10.1152/ajpheart.00121.2011

Rindler, T. N., Lasko, V. M., Nieman, M. L., Okada, M., Lorenz, J. N., and Lingrel, J. B. (2013). Knockout of the Na,K-ATPase alpha2-isoform in cardiac myocytes delays pressure overload-induced cardiac dysfunction. Am. J. Physiol. Heart Circ. Physiol. 304, H1147-H1158. doi: 10.1152/ajpheart.00594.2012

Rizo, J., and Südhof, T. C. (2002). Snares and Munc18 in synaptic vesicle fusion. Nat. Rev. Neurosci. 3, 641-653. doi: 10.1038/nrn898

Rose, E. M., Koo, J. C., Antflick, J. E., Ahmed, S. M., Angers, S., and Hampson, D. R. (2009). Glutamate transporter coupling to Na,K-ATPase. J. Neurosci. 29, 8143-8155. doi: 10.1523/JNEUROSCI.1081-09.2009

Sagar, A., and Rakowski, R. F. (1994). Access channel model for the voltage dependence of the forward-running $\mathrm{Na}^{+} / \mathrm{K}^{+}$pump. J. Gen. Physiol. 103, 869-893. doi: 10.1085/jgp.103.5.869

Santoro, L., Manganelli, F., Fortunato, M. R., Soldovieri, M. V., Ambrosino, P., Iodice, R., et al. (2011). A new Italian FHM2 family: clinical aspects and functional analysis of the disease-associated mutation. Cephalalgia 31, 808-819. doi: $10.1177 / 0333102411399351$

Schack, V. R., Holm, R., and Vilsen, B. (2012). Inhibition of phosphorylation of $\mathrm{Na}^{+}, \mathrm{K}^{+}$-ATPase by mutations causing familial hemiplegic migraine. J. Biol. Chem. 287, 2191-2202. doi: 10.1074/jbc.M111.323022 
Segall, L., Mezzetti, A., Scanzano, R., Gargus, J. J., Purisima, E., and Blostein, R. (2005). Alterations in the alpha2 isoform of Na,K-ATPase associated with familial hemiplegic migraine type 2. Proc. Natl. Acad. Sci. U.S.A. 102, 11106-11111. doi: 10.1073/pnas.0504323102

Shattock, M. J., Ottolia, M., Bers, D. M., Blaustein, M. P., Boguslavskyi, A., Bossuyt, J., et al. (2015). $\mathrm{Na}^{+} / \mathrm{Ca}^{2+}$ exchange and $\mathrm{Na}^{+} / \mathrm{K}^{+}$-ATPase in the heart. J. Physiol. 593, 1361-1382. doi: 10.1113/jphysiol.2014.282319

Shelly, D. A., He, S., Moseley, A., Weber, C., Stegemeyer, M., Lynch, R. M., et al. (2004). $\mathrm{Na}^{+}$pump alpha 2 -isoform specifically couples to contractility in vascular smooth muscle: evidence from gene-targeted neonatal mice. Am. J. Physiol. Cell Physiol. 286, C813-C820. doi: 10.1152/ajpcell.003 89.2003

Shinoda, T., Ogawa, H., Cornelius, F., and Toyoshima, C. (2009). Crystal structure of the sodium-potassium pump at $2.4 \AA$ resolution. Nature 459, 446-450. doi: $10.1038 /$ nature07939

Skou, J. C. (1957). The influence of some cations on an adenosine triphosphatase from peripheral nerves. Biochim. Biophys. Acta 23, 394-401. doi: 10.1016/00063002(57) $90343-8$

Skou, J. C. (1990). The fourth Datta lecture. The energy coupled exchange of $\mathrm{Na}^{+}$ for $\mathrm{K}^{+}$across the cell membrane. The $\mathrm{Na}^{+}, \mathrm{K}^{+}$-pump. FEBS Lett. 268, 314-324. doi: 10.1016/0014-5793(90)81278-V

Song, H., Lee, M. Y., Kinsey, S. P., Weber, D. J., and Blaustein, M. P. (2006). An $\mathrm{N}$-terminal sequence targets and tethers $\mathrm{Na}^{+}$pump alpha2-subunits to specialized plasma membrane microdomains. J. Biol. Chem. 281, 12929-12940. doi: $10.1074 /$ jbc.M507450200

Spiller, S., and Friedrich, T. (2014). Functional analysis of human $\mathrm{Na}^{+} / \mathrm{K}^{+}$ATPase familial or sporadic hemiplegic migraine mutations expressed in Xenopus oocytes. World J. Biol. Chem. 5, 240-253. doi: 10.4331/wjbc.v5. i2.240

Stanley, C. M., Gagnon, D. G., Bernal, A., Meyer, D. J., Rosenthal, J. J., and Artigas, P. (2015). Importance of the voltage dependence of cardiac $\mathrm{Na} / \mathrm{K}$ ATPase isozymes. Biophys. J. 109, 1852-1862. doi: 10.1016/j.bpj.2015. 09.015

Stühmer, W., and Parekh, A. B. (1995). "Electrophysiological recordings from Xenopus oocytes," in Single-Channel Recording, 2nd Edn., eds B. Sakmann and E. Neher (New York, NY; London: Plenum Press), 341-355.

Suzuki, M., Van Paesschen, W., Stalmans, I., Horita, S., Yamada, H., Bergmans, B. A., et al. (2010). Defective membrane expression of the $\mathrm{Na}^{+}-\mathrm{HCO}_{3}^{-}$ cotransporter NBCe1 is associated with familial migraine. Proc. Natl. Acad. Sci. U.S.A. 107, 15963-15968. doi: 10.1073/pnas.1008705107

Swarts, H. G., Weigand, K. M., Venselaar, H., van den Maagdenberg, A. M., Russel, F. G., and Koenderink, J. B. (2013). Familial hemiplegic migraine mutations affect Na,K-ATPase domain interactions. Biochim. Biophys. Acta 1832, 2173-2179. doi: 10.1016/j.bbadis.2013.08.003

Sweadner, K. J., and Rael, E. (2000). The FXYD gene family of small ion transport regulators or channels: cDNA sequence, protein signature sequence, and expression. Genomics 68, 41-56. doi: 10.1006/geno.2000.6274

Swoboda, K. J., Kanavakis, E., Xaidara, A., Johnson, J. E., Leppert, M. F., Schlesinger-Massart, M. B., et al. (2004). Alternating hemiplegia of childhood or familial hemiplegic migraine? A novel ATP1A2 mutation. Ann. Neurol. 55, 884-887. doi: 10.1002/ana.20134

Tavraz, N. N., Dürr, K. L., Koenderink, J. B., Freilinger, T., Bamberg, E., Dichgans, M., et al. (2009). Impaired plasma membrane targeting or protein stability by certain ATP1A2 mutations identified in sporadic or familial hemiplegic migraine. Channels 3, 82-87. doi: 10.4161/chan.3.2.8085

Tavraz, N. N., Friedrich, T., Dürr, K. L., Koenderink, J. B., Bamberg, E., Freilinger, T., et al. (2008). Diverse functional consequences of mutations in the $\mathrm{Na}^{+} / \mathrm{K}^{+}$. ATPase alpha2-subunit causing familial hemiplegic migraine type 2. J. Biol. Chem. 283, 31097-31106. doi: 10.1074/jbc.M802771200

Todt, U., Dichgans, M., Jurkat-Rott, K., Heinze, A., Zifarelli, G., Koenderink, J. B., et al. (2005). Rare missense variants in ATP1A2 in families with clustering of common forms of migraine. Hum. Mutat. 26, 315-321. doi: 10.1002/humu.20229

Tottene, A., Conti, R., Fabbro, A., Vecchia, D., Shapovalova, M., Santello, M., et al. (2009). Enhanced excitatory transmission at cortical synapses as the basis for facilitated spreading depression in $\mathrm{Ca}_{v} 2.1$ knockin migraine mice. Neuron 61, 762-773. doi: 10.1016/j.neuron.2009.01.027
Toustrup-Jensen, M. S., Einholm, A. P., Schack, V. R., Nielsen, H. N., Holm, R., Sobrido, M. J., et al. (2014). Relationship between intracellular $\mathrm{Na}^{+}$concentration and reduced $\mathrm{Na}^{+}$affinity in $\mathrm{Na}^{+}, \mathrm{K}^{+}$-ATPase mutants causing neurological disease. J. Biol. Chem. 289, 3186-3197. doi: $10.1074 /$ jbc.M1 13.543272

Toustrup-Jensen, M. S., Holm, R., Einholm, A. P., Schack, V. R., Morth, J. P., Nissen, P., et al. (2009). The C terminus of $\mathrm{Na}^{+}, \mathrm{K}^{+}$-ATPase controls $\mathrm{Na}^{+}$ affinity on both sides of the membrane through Arg935. J. Biol. Chem. 284, 18715-18725. doi: 10.1074/jbc.M109.015099

Ullah, G., Cressman, J. R. Jr., Barreto, E., and Schiff, S. J. (2009). The influence of sodium and potassium dynamics on excitability, seizures, and the stability of persistent states. II. Network and glial dynamics. J. Comput. Neurosci. 26, 171-183. doi: 10.1007/s10827-008-0130-6

Ullah, G., Wei, Y., Dahlem, M. A., Wechselberger, M., and Schiff, S. J. (2015). The role of cell volume in the dynamics of seizure, spreading depression, and anoxic depolarization. PLoS Comput. Biol. 11:e1004414. doi: 10.1371/journal.pcbi.1004414

van den Maagdenberg, A. M., Pietrobon, D., Pizzorusso, T., Kaja, S., Broos, L. A., Cesetti, T., et al. (2004). A Cacnala knockin migraine mouse model with increased susceptibility to cortical spreading depression. Neuron 41, 701-710. doi: 10.1016/S0896-6273(04)00085-6

van den Maagdenberg, A. M., Pizzorusso, T., Kaja, S., Terpolilli, N., Shapovalova, M., Hoebeek, F. E., et al. (2010). High cortical spreading depression susceptibility and migraine-associated symptoms in $\mathrm{Ca}_{\mathrm{v}} 2.1 \mathrm{~S} 218 \mathrm{~L}$ mice. Ann. Neurol. 67, 85-98. doi: 10.1002/ana.21815

Vanmolkot, K. R., Kors, E. E., Hottenga, J. J., Terwindt, G. M., Haan, J., Hoefnagels, W. A., et al. (2003). Novel mutations in the $\mathrm{Na}^{+}, \mathrm{K}^{+}$-ATPase pump gene ATP1A2 associated with familial hemiplegic migraine and benign familial infantile convulsions. Ann. Neurol. 54, 360-366. doi: 10.1002/ana.10674

Vanmolkot, K. R., Kors, E. E., Turk, U., Turkdogan, D., Keyser, A., Broos, L. A., et al. (2006a). Two de novo mutations in the Na,K-ATPase gene ATP1A2 associated with pure familial hemiplegic migraine. Eur. J. Hum. Genet. 14, 555-560. doi: 10.1038/sj.ejhg.5201607

Vanmolkot, K. R., Stam, A. H., Raman, A., Koenderink, J. B., de Vries, B., van den Boogerd, E. H., et al. (2007). First case of compound heterozygosity in $\mathrm{Na}, \mathrm{K}-$ ATPase gene ATP1A2 in familial hemiplegic migraine. Eur. J. Hum. Genet. 15, 884-888. doi: 10.1038/sj.ejhg.5201841

Vanmolkot, K. R., Stroink, H., Koenderink, J. B., Kors, E. E., van den Heuvel, J. J., van den Boogerd, E. H., et al. (2006b). Severe episodic neurological deficits and permanent mental retardation in a child with a novel FHM2 ATP1A2 mutation. Ann. Neurol. 59, 310-314. doi: 10.1002/ana.20760

Vasilyev, A., Khater, K., and Rakowski, R. F. (2004). Effect of extracellular pH on presteady-state and steady-state current mediated by the $\mathrm{Na}^{+} / \mathrm{K}^{+}$pump. J. Membr. Biol. 198, 65-76. doi: 10.1007/s00232-004-0660-4

Vedovato, N., and Gadsby, D. C. (2010). The two C-terminal tyrosines stabilize occluded $\mathrm{Na} / \mathrm{K}$ pump conformations containing Na or K ions. J. Gen. Physiol. 136, 63-82. doi: 10.1085/jgp.201010407

Vedovato, N., and Gadsby, D. C. (2014). Route, mechanism, and implications of proton import during $\mathrm{Na}^{+} / \mathrm{K}^{+}$exchange by native $\mathrm{Na}^{+} / \mathrm{K}^{+}$-ATPase pumps. J. Gen. Physiol. 143, 449-464. doi: 10.1085/jgp.201311148

Vilsen, B. (1995). Mutant Glu781->Ala of the rat kidney $\mathrm{Na}^{+}, \mathrm{K}^{+}$-ATPase displays low cation affinity and catalyzes ATP hydrolysis at a high rate in the absence of potassium ions. Biochemistry 34, 1455-1463. doi: 10.1021/bi0000 $4 \mathrm{a} 041$

Wang, X., and Horisberger, J. D. (1995). A conformation of $\mathrm{Na}^{+}-\mathrm{K}^{+}$pump is permeable to proton. Am. J. Physiol. Cell Physiol. 268, C590-C595.

Wei, Y., Ullah, G., and Schiff, S. J. (2014). Unification of neuronal spikes, seizures, and spreading depression. J. Neurosci. 34, 11733-11743. doi: 10.1523/JNEUROSCI.0516-14.2014

Weigand, K. M., Laursen, M., Swarts, H. G., Engwerda, A. H., Prüfert, C., Sandrock, J., et al. (2014a). $\mathrm{Na}^{+}, \mathrm{K}^{+}$-ATPase isoform selectivity for digitalislike compounds is determined by two amino acids in the first extracellular loop. Chem. Res. Toxicol. 27, 2082-2092. doi: 10.1021/tx500290k

Weigand, K. M., Swarts, H. G., Russel, F. G., and Koenderink, J. B. (2014b). Biochemical characterization of sporadic/familial hemiplegic migraine mutations. Biochim. Biophys. Acta 1838, 1693-1700. doi: $10.1016 /$ j.bbamem.2014.03.022 
Withering, W. (1785). An Account on the Foxglove and some of Its Medical Uses: With Practical Remarks on Dropsy and Other Diseases. (Birmingham: Printed by M. Swinney for G.G.J. and J. Robinson). London: Paternoster-Row.

Wuddel, I., and Apell, H. J. (1995). Electrogenicity of the sodium transport pathway in the Na,K-ATPase probed by charge-pulse experiments. Biophys. J. 69, 909-921. doi: 10.1016/S0006-3495(95)79965-9

Yaragatupalli, S., Olivera, J. F., Gatto, C., and Artigas, P. (2009). Altered $\mathrm{Na}^{+}$ transport after an intracellular alpha-subunit deletion reveals strict external sequential release of $\mathrm{Na}^{+}$from the $\mathrm{Na} / \mathrm{K}$ pump. Proc. Natl. Acad. Sci. U.S.A. 106, 15507-15512. doi: 10.1073/pnas.0903752106
Conflict of Interest Statement: The authors declare that the research was conducted in the absence of any commercial or financial relationships that could be construed as a potential conflict of interest.

Copyright (c) 2016 Friedrich, Tavraz and Junghans. This is an open-access article distributed under the terms of the Creative Commons Attribution License (CC BY). The use, distribution or reproduction in other forums is permitted, provided the original author(s) or licensor are credited and that the original publication in this journal is cited, in accordance with accepted academic practice. No use, distribution or reproduction is permitted which does not comply with these terms. 